أثر بعض المتغيرات الثخصية على درجة الاستفادة من الجمعيات الأهلية في نثاط محو الأمية (در اسة ميدانية ببعض قرى الاسفراد محافظة أسيوط)

إبراهيم عبدالرحمن علي خليفة، محمد محمد إسماعيل عبدالحافظ، حسن عبدالعاطي محمد، عبده رمضان عبد الله جمعة عبة

قسم الإرشاد الزر اعي و المجتمع الريفي - كلية الزراعة - جامعة الأزهر فرعة أسيوط

Received on: $14 / 9 / 2017$

Accepted for publication on: 3/10/2017

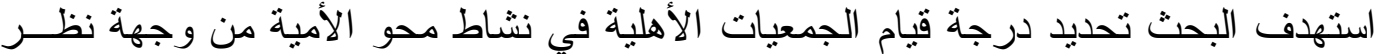

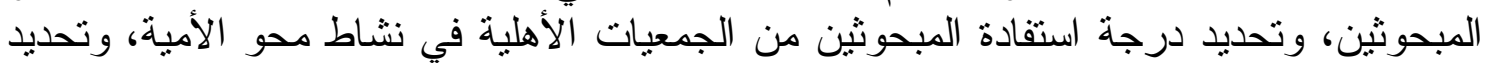

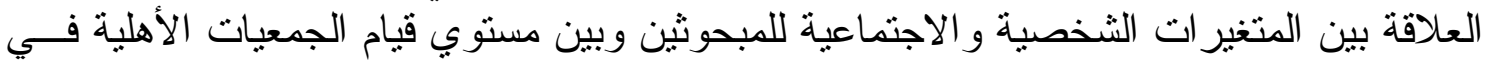

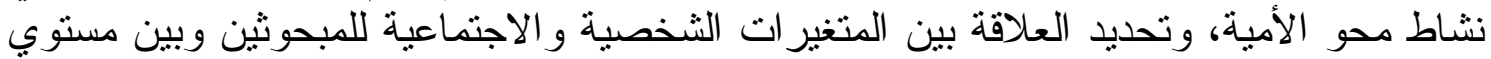

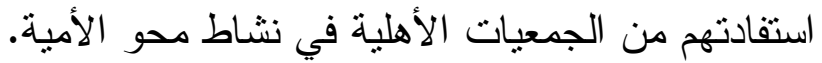

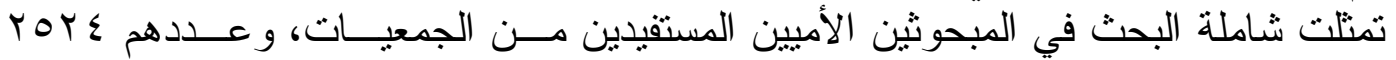

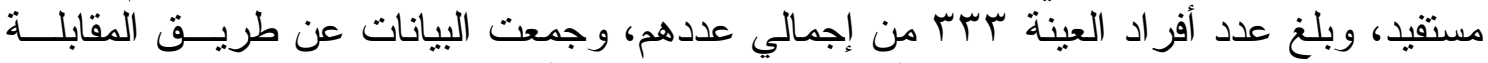

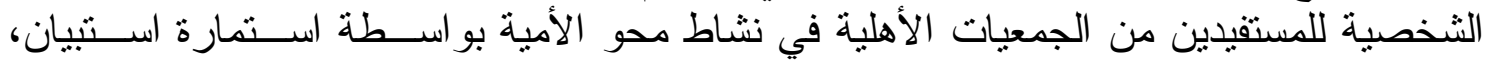

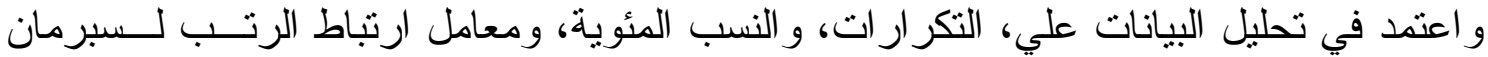

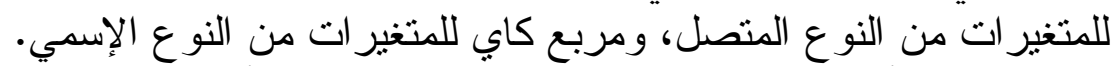

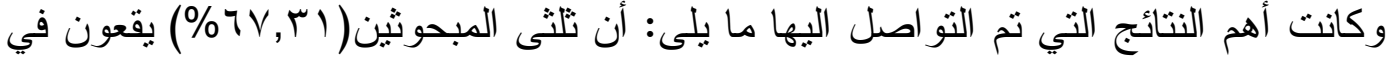

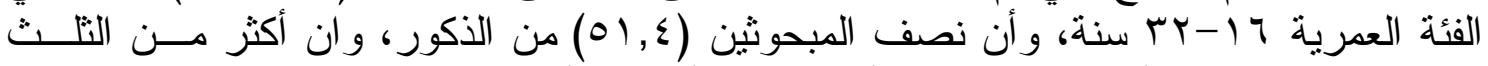

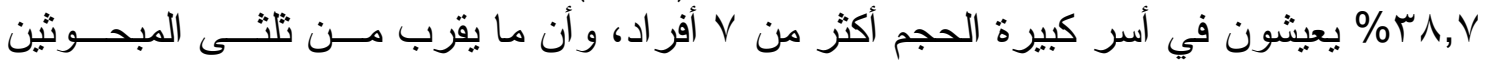

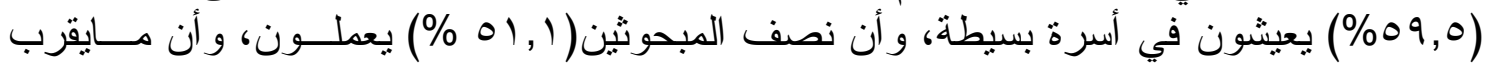

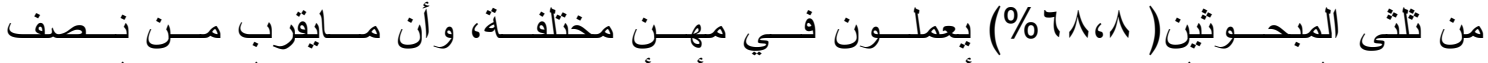

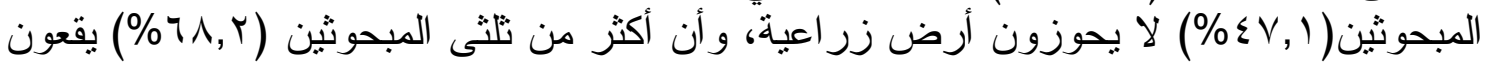

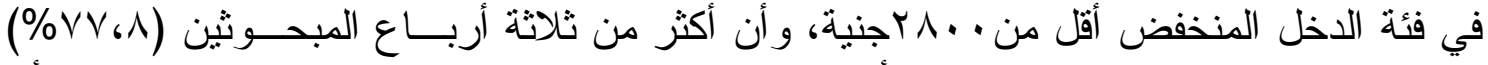

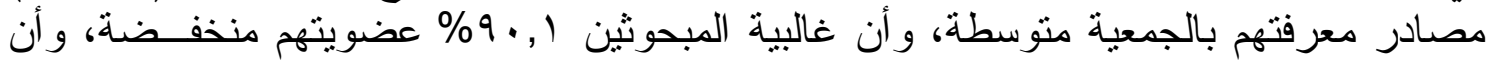

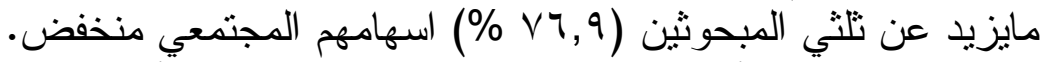

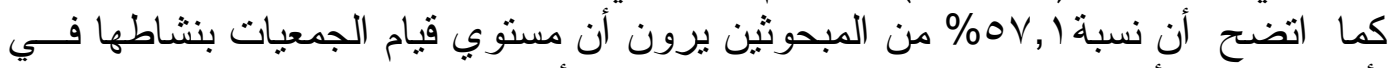

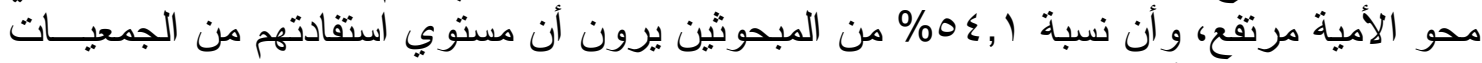
بنشاطها في محو الأمية مرتفع.

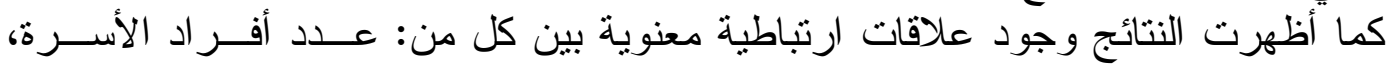

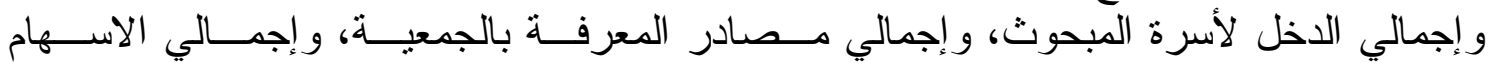

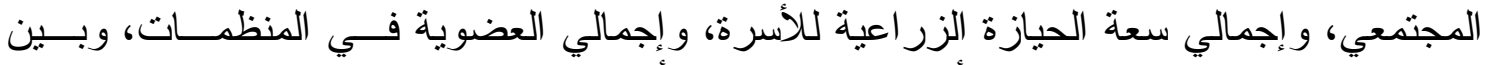
مستوي أستفادتهم من الجمعيات الأهلية بنشاط محو الزية الأمية.

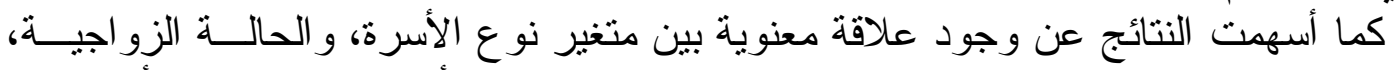
و الحالة العملية، و المهنة، و النوع، و وستفادة المبحوثين من الجمعية الأهلية بنشاط محو الألئة لأمية.

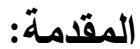

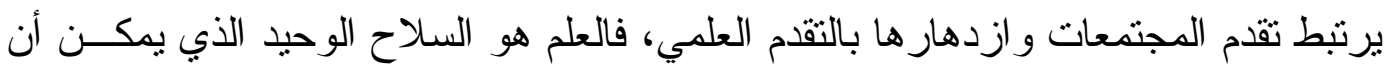

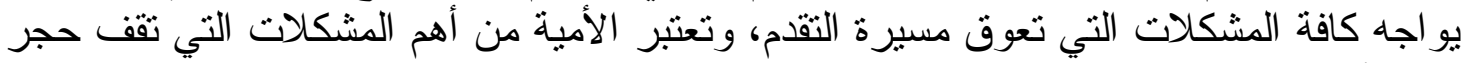

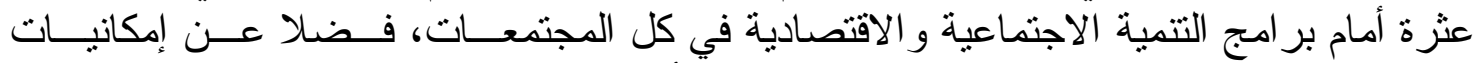

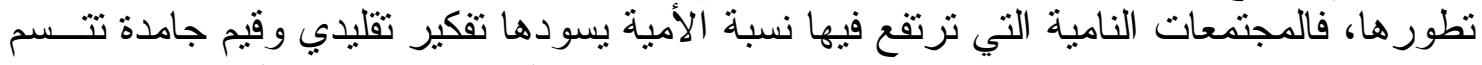

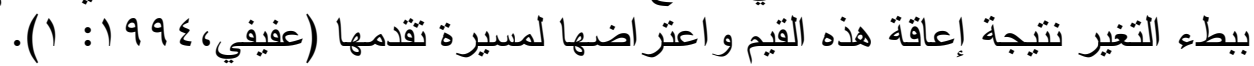




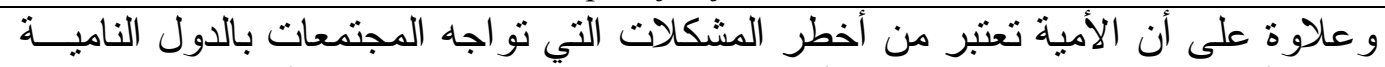

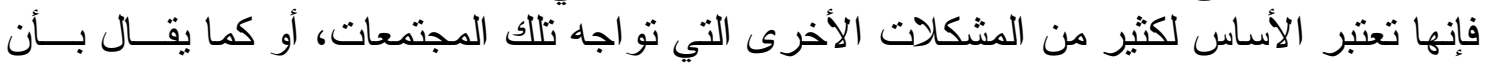

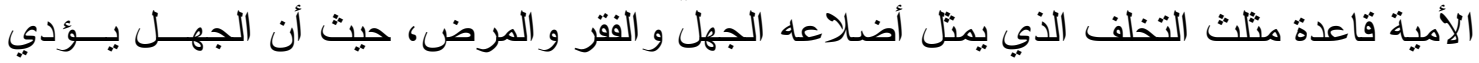

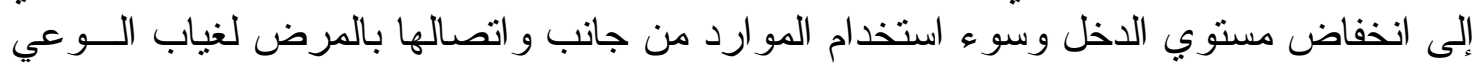

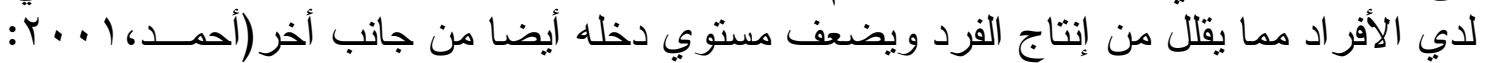

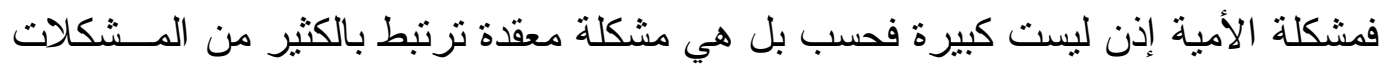

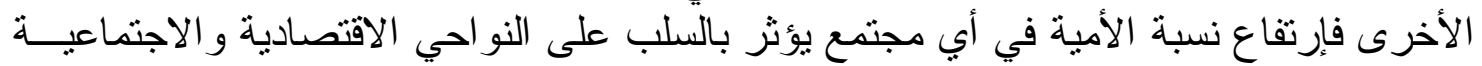

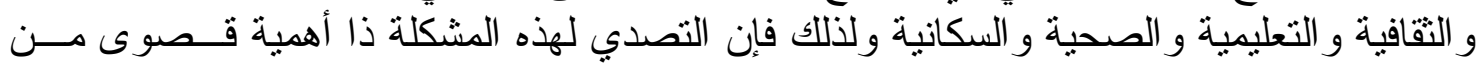

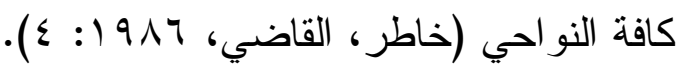

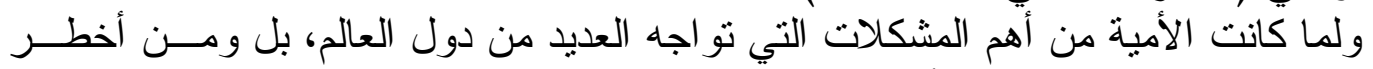

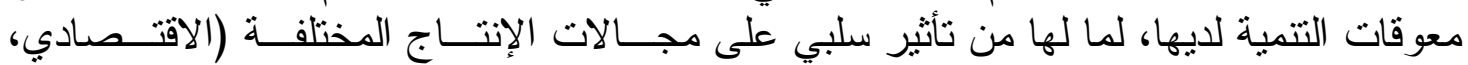

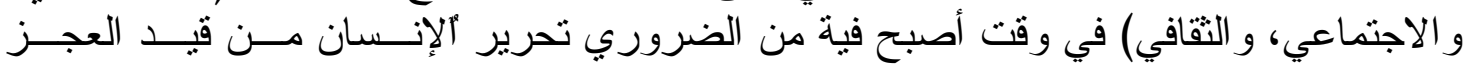

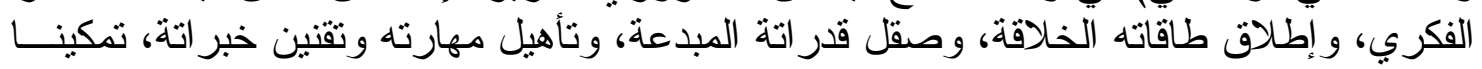

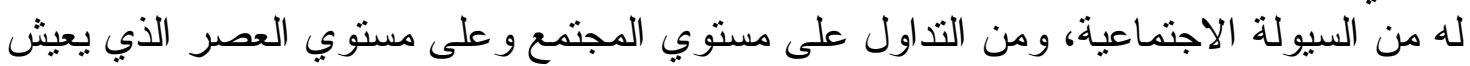

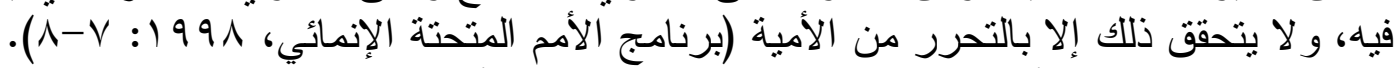

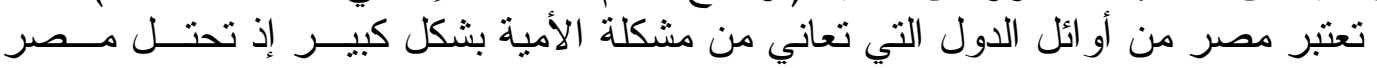

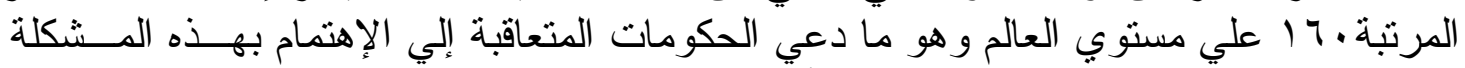

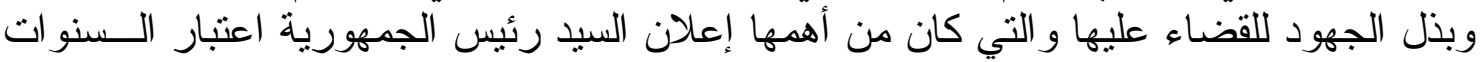

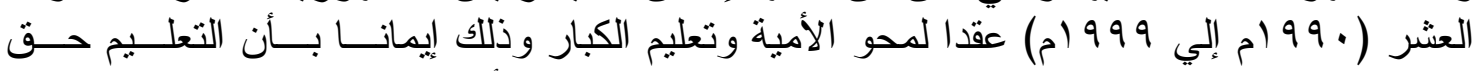

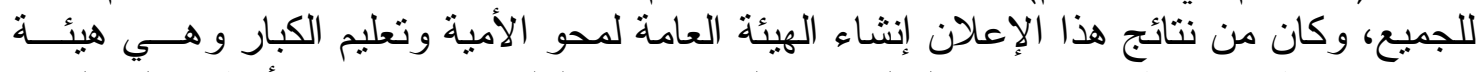

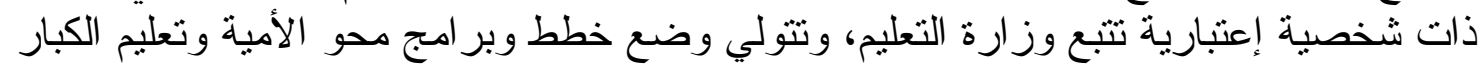

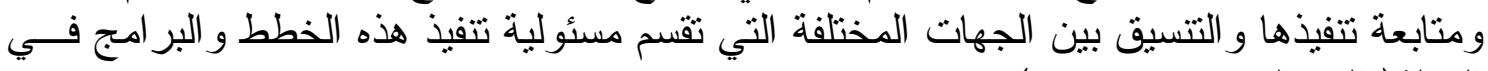

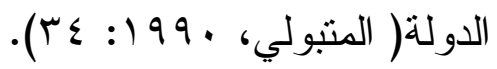

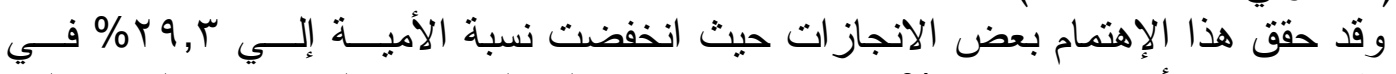

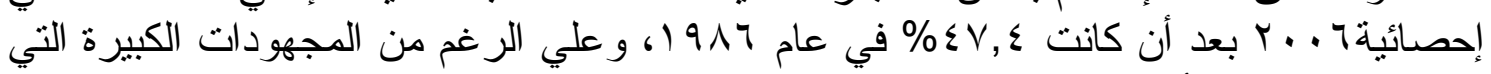

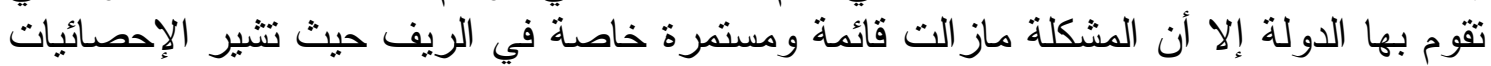

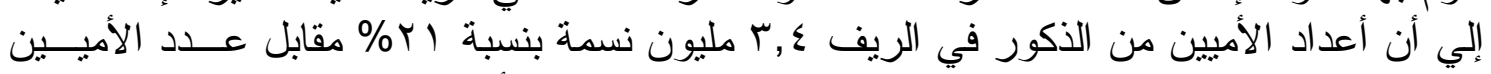

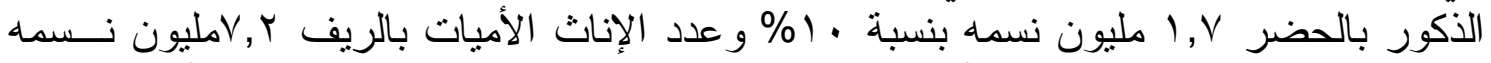

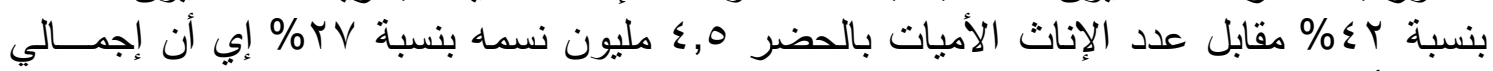

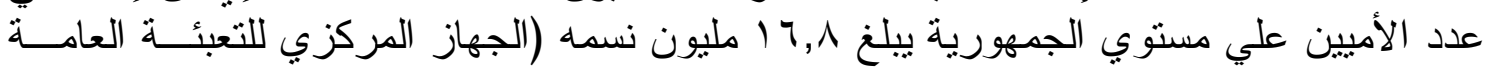

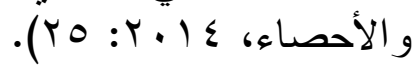

و لا شكك أن هذه الأعداد الكبيرة من الأميين تبرز خطورة المشكلة على مستوي الجمهورية

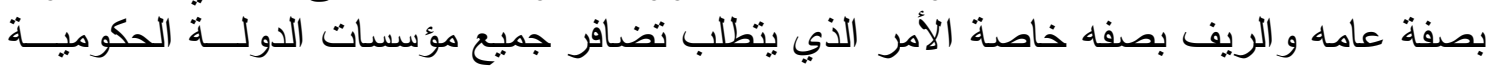

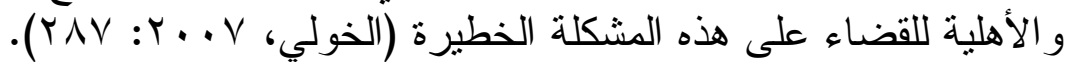

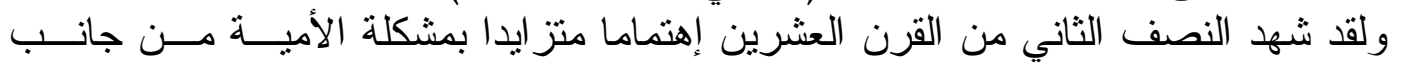

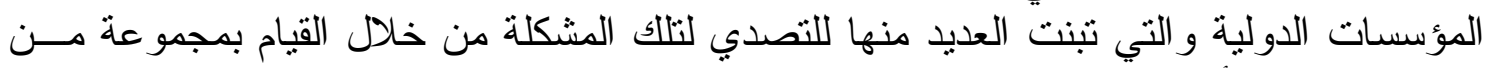

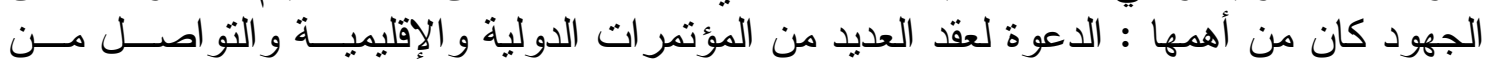

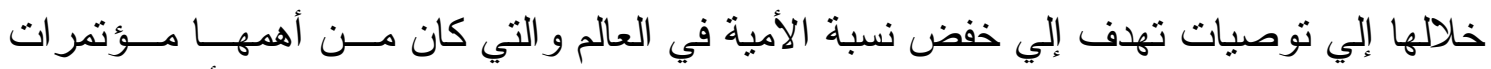

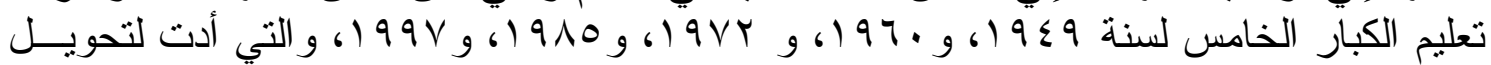

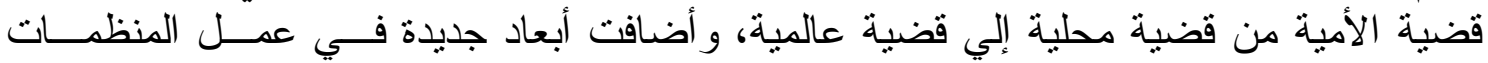




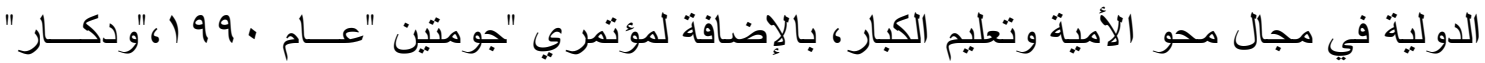

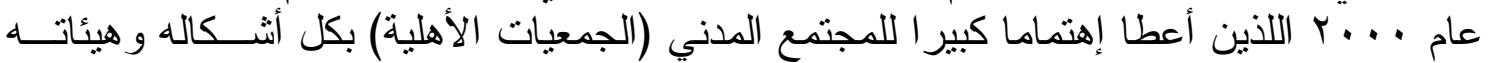

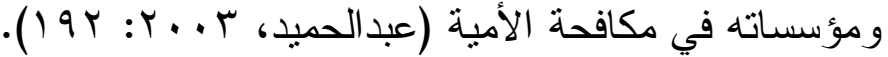

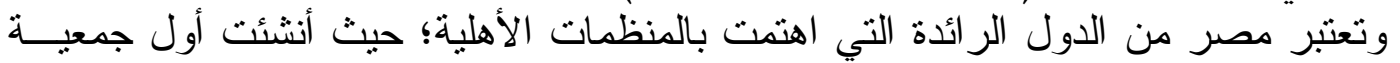

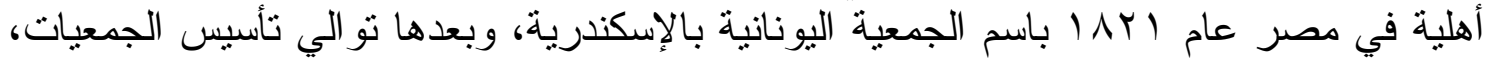

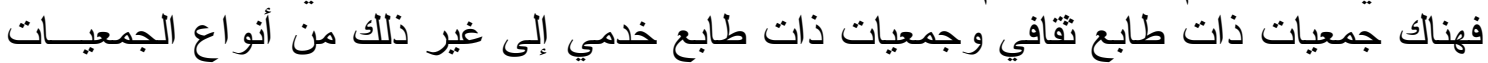

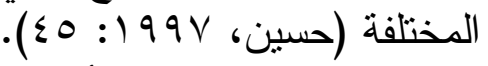

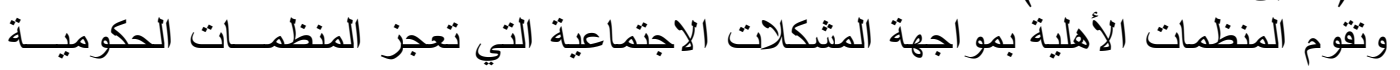

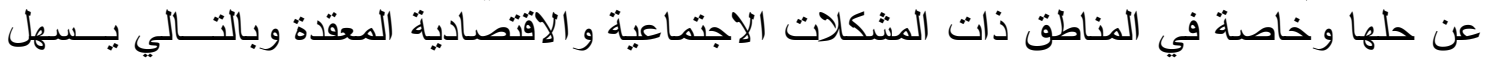

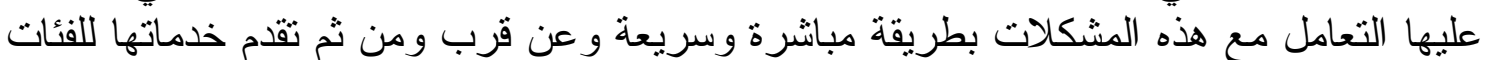

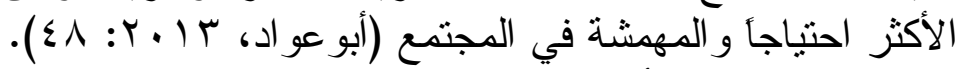

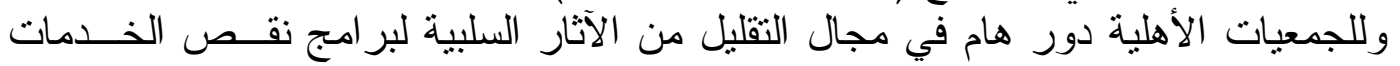

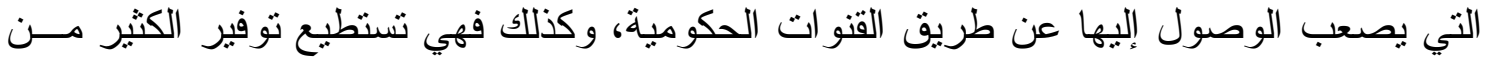

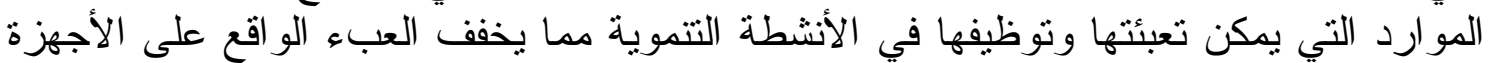

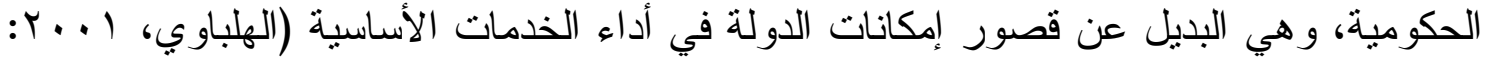

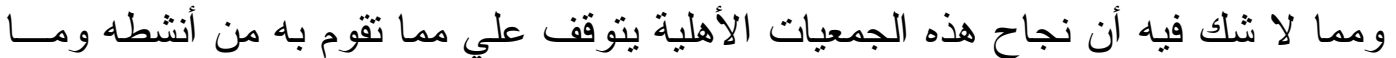

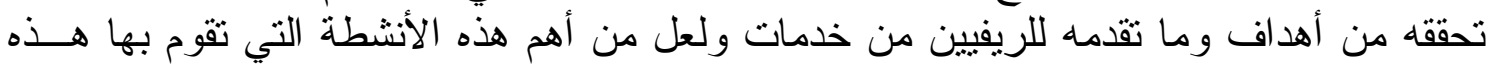

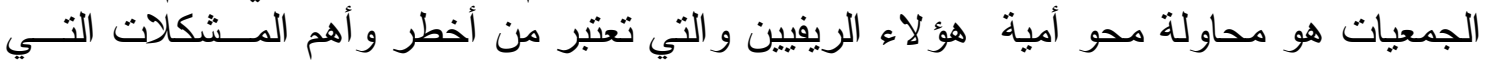

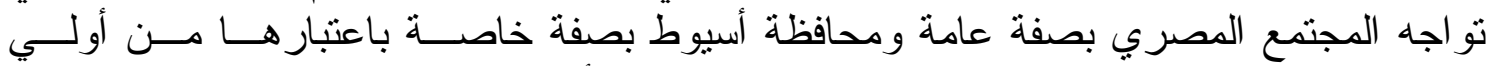

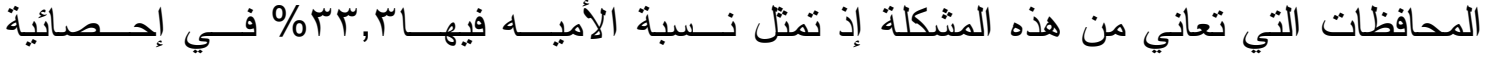

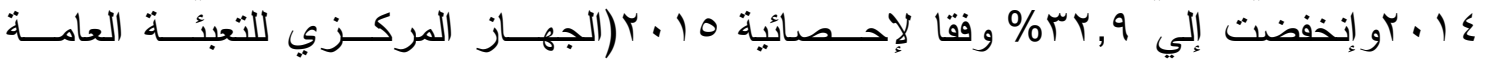

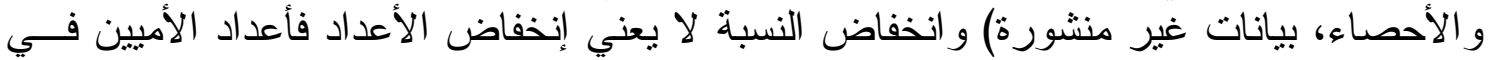

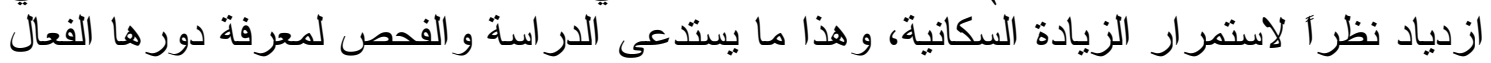

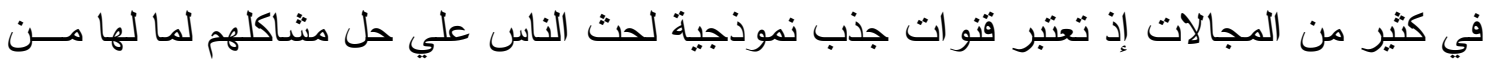

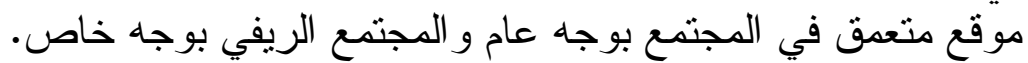

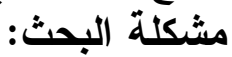

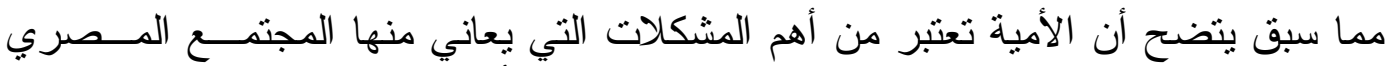

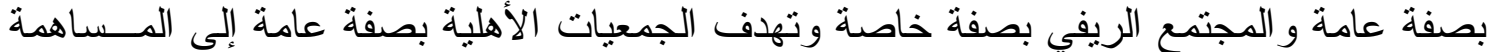

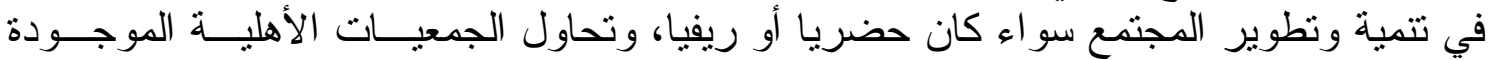

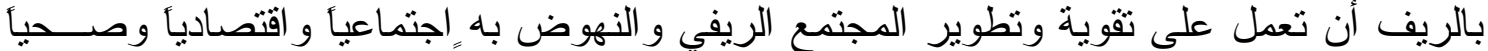

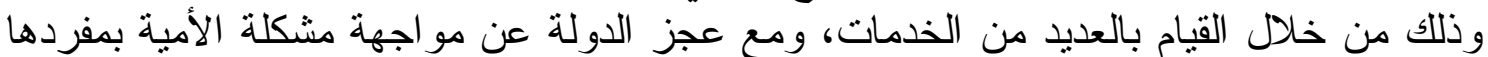

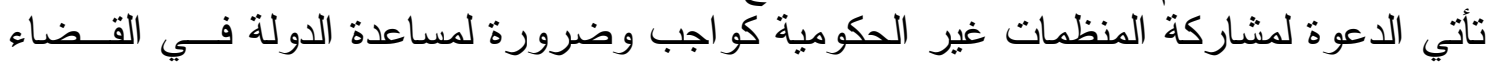

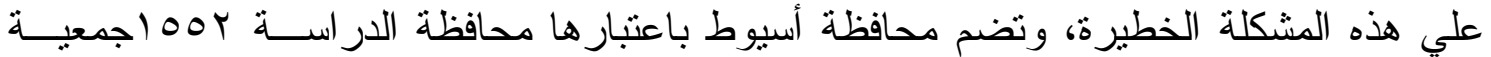

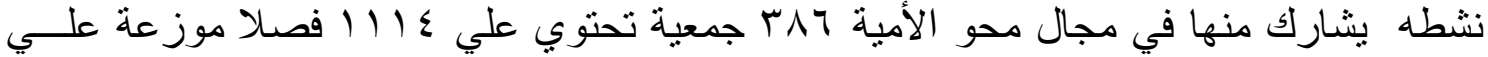

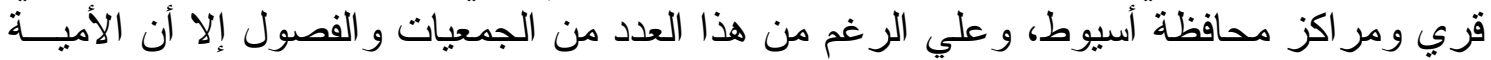

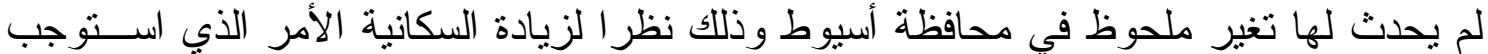

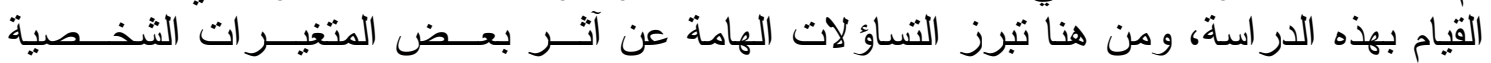

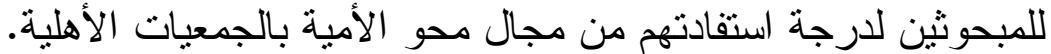

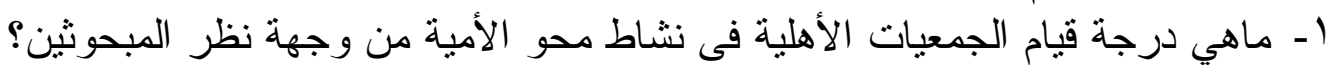
r ا - ماهي درجة استفادة المبحوثين من الجمعيات الأهلية في نشاط محو الأمية؛ 


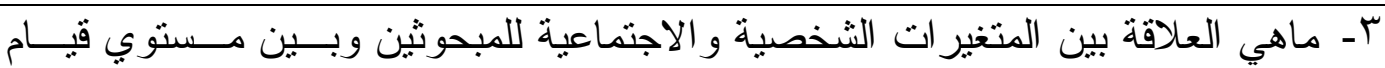

الجمعيات الأهلية في نشاط محو الأمية؛

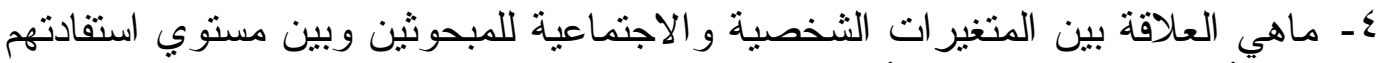

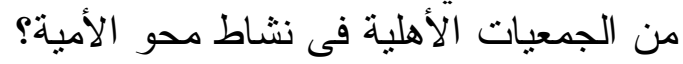

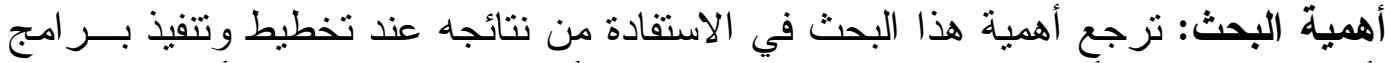

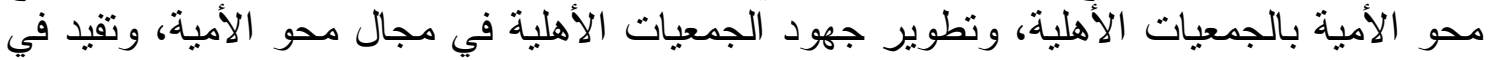

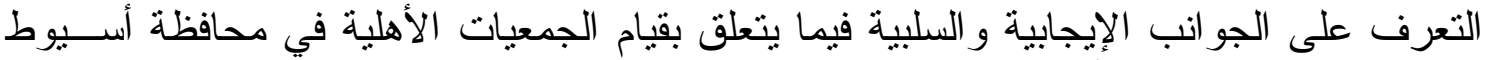
بدور ها في مجال محو الأمية بين الريفية الإلينية.

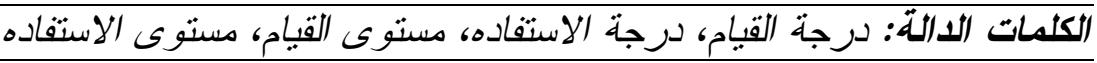

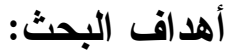

1 - تحديد درجة قيام الجمعيات الأهلية بنشاط محو الأمية من وجهة نظر المبحوثين.

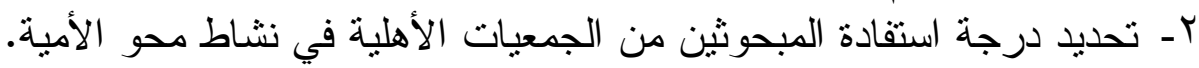

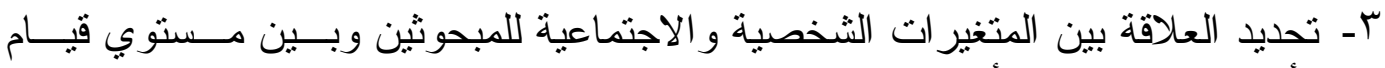
الجمعيات الأهلية بنشاط محو الأمية. ع - تحديد العلاقة بين المتغير ات الثخية الثخية و الاجتماعية للمبحوثين وبين مستوي استفادتهم

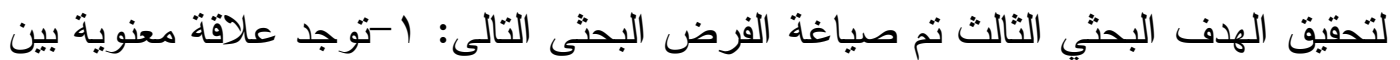

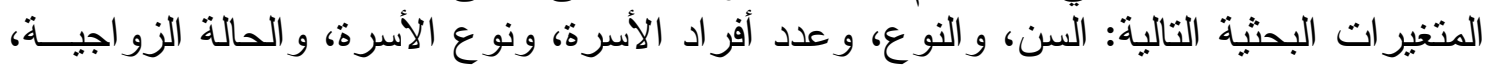

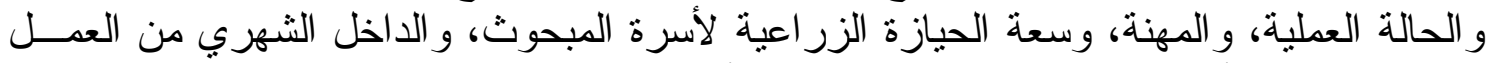

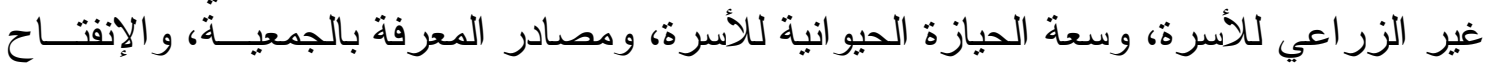

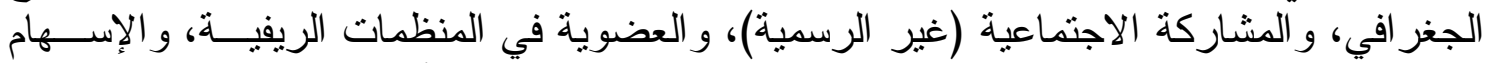

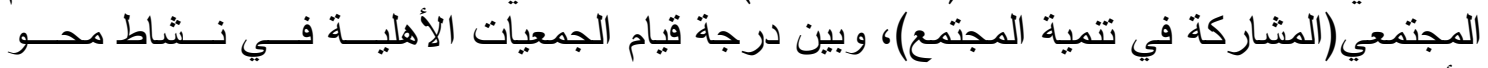

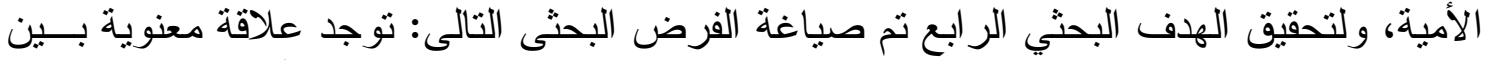

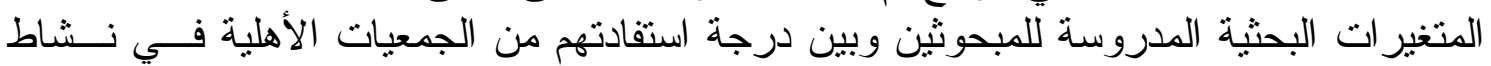

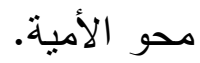

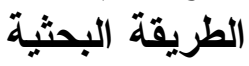

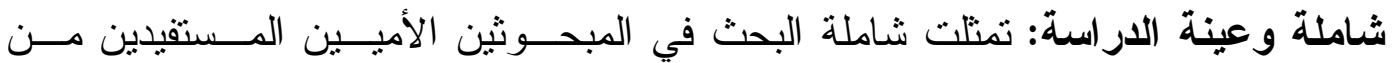

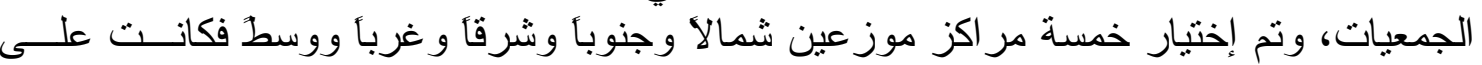

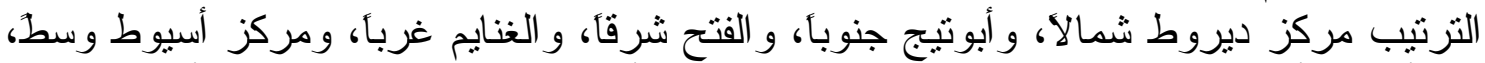

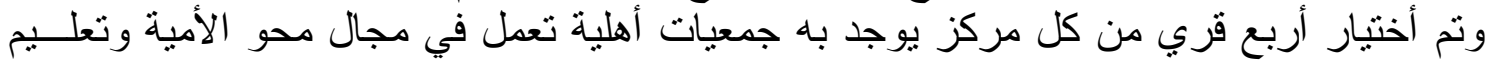

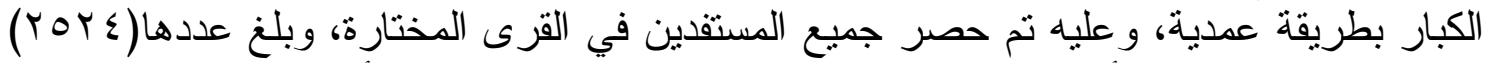

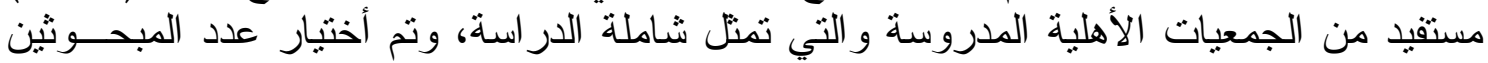

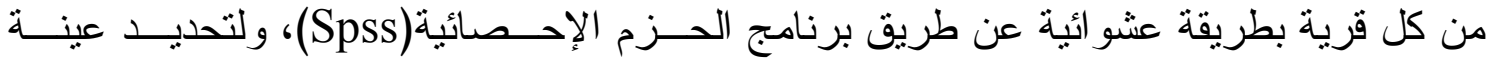

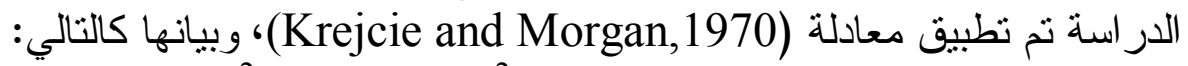
$\mathrm{S}=\mathrm{X}^{2} \mathrm{NP}(1-\mathrm{P}) \div \mathrm{d}^{2}(\mathrm{~N}-1)+\mathrm{X}^{2} \mathrm{P}(1-\mathrm{P})$

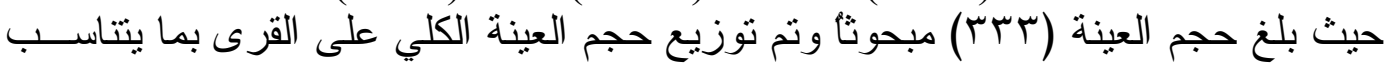

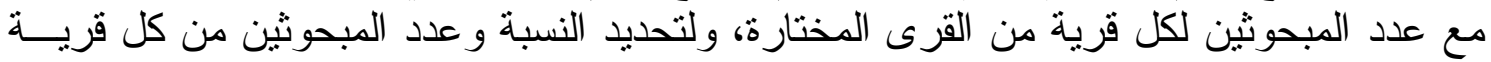

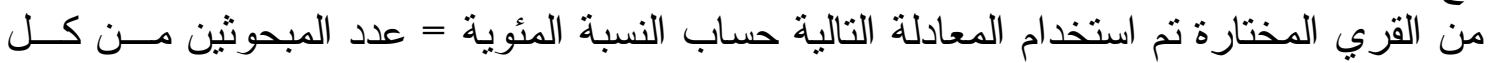


قرية × ×. 1 بـ الثاملة، عدد المبحوثين المختارين= العينة ٪ الثاملة ×عدد المبحوثين المستفيدين

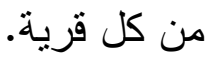

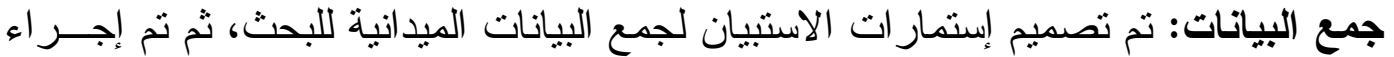

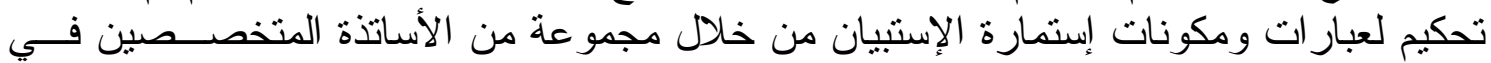

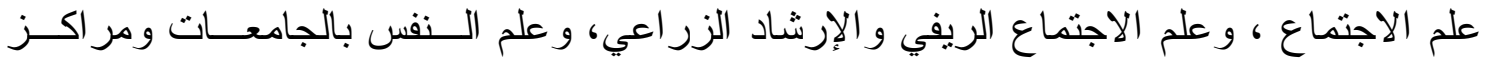

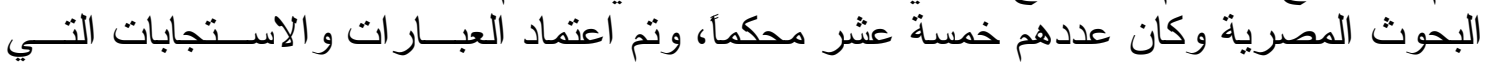

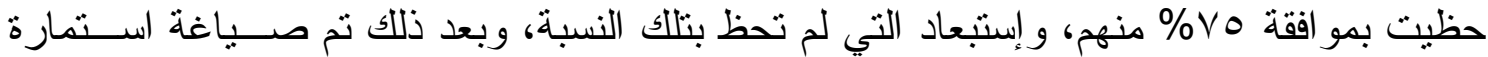

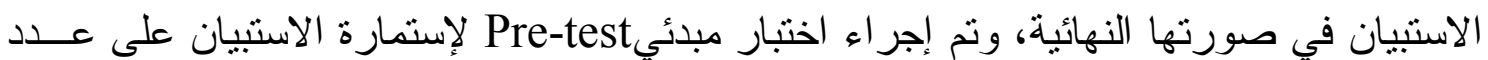

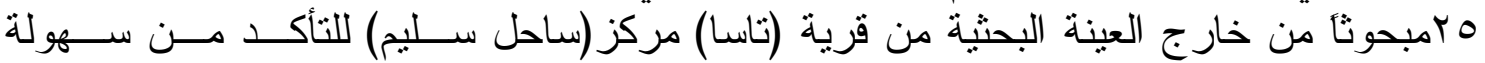

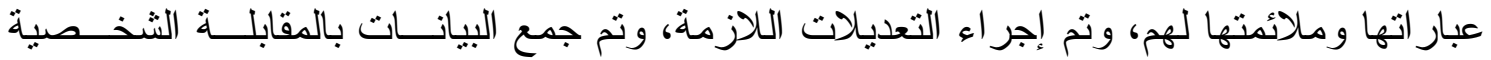

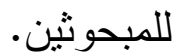

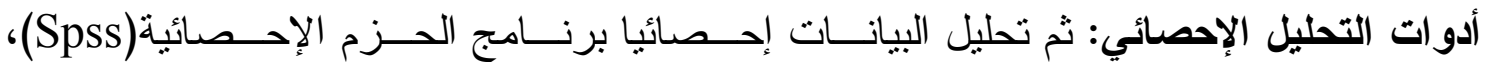

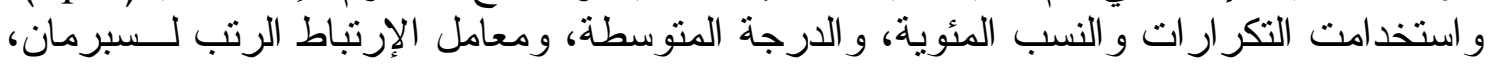

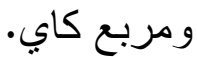

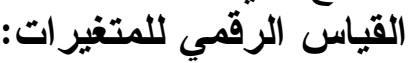

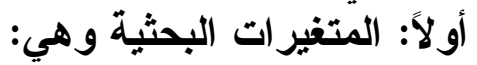

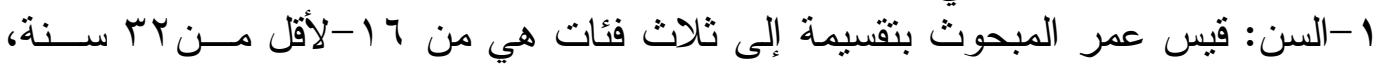

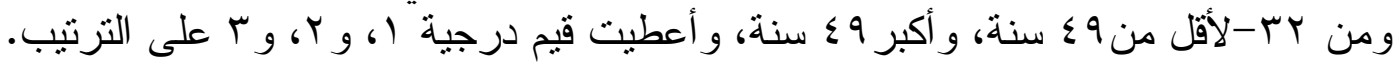

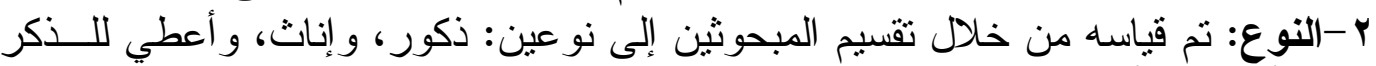

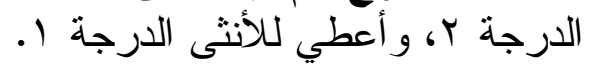

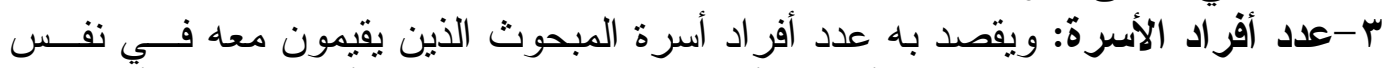

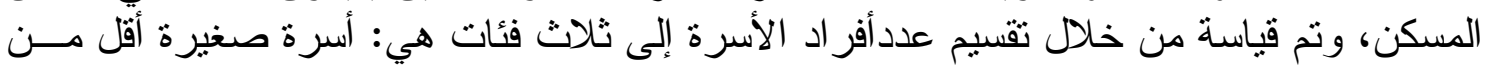

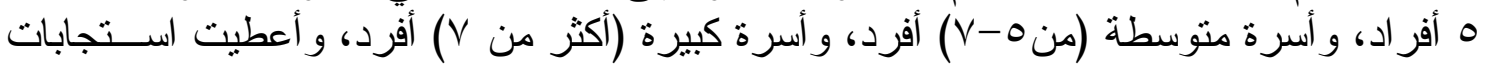

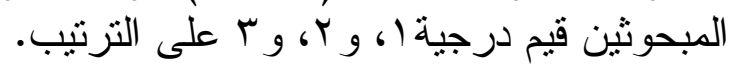

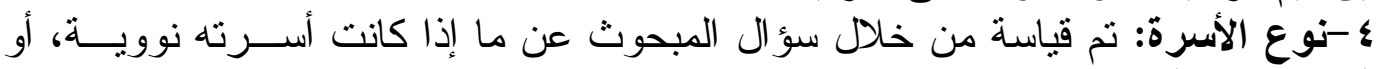

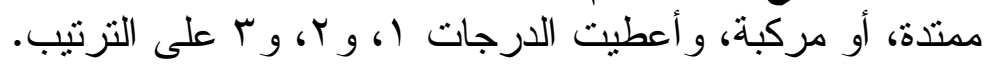

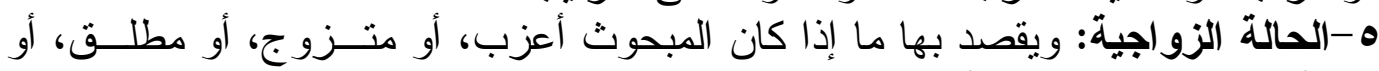

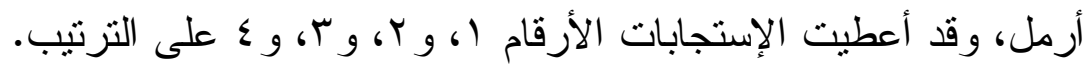

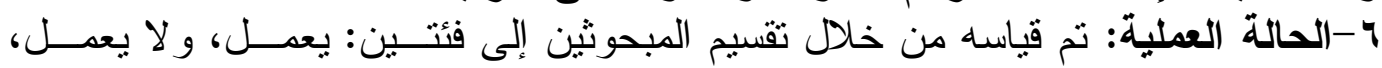

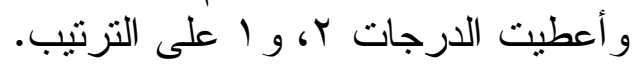

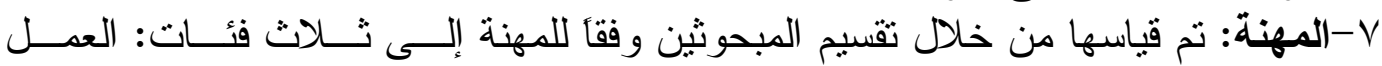

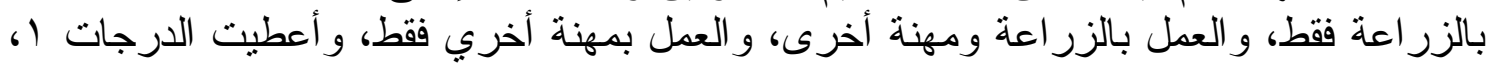

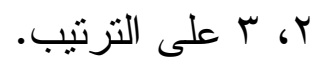

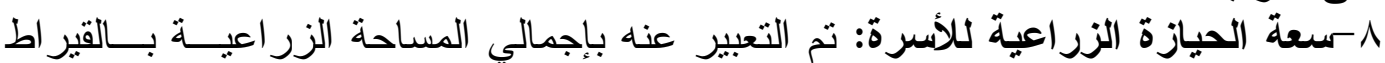

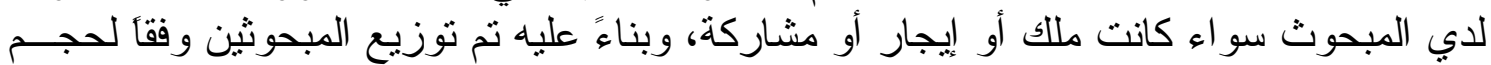

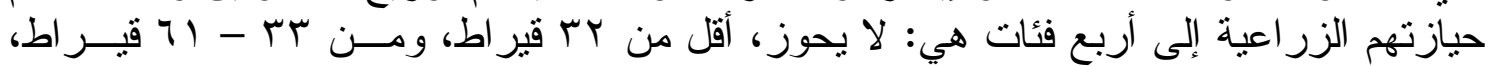

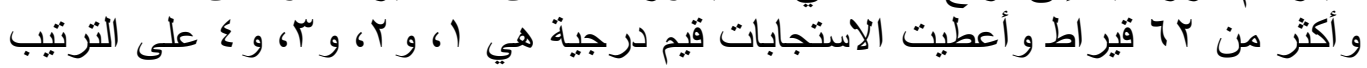

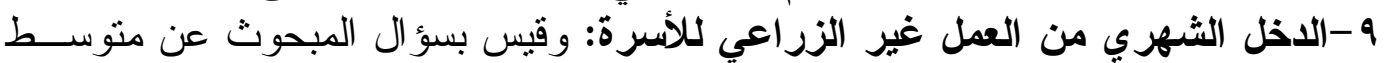

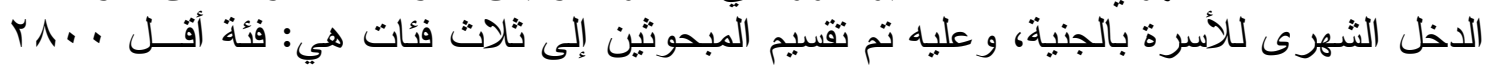

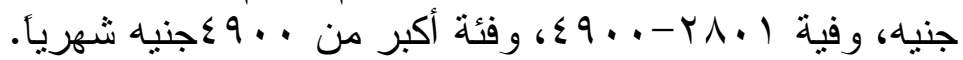




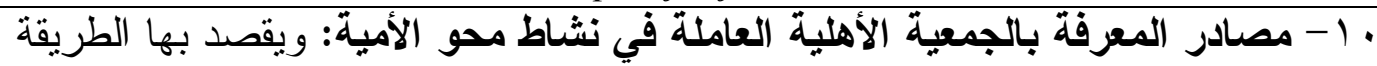

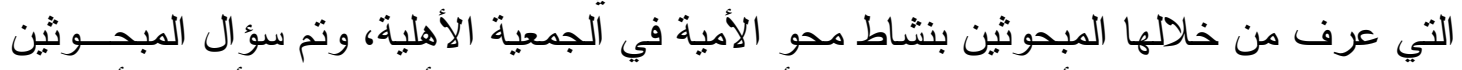

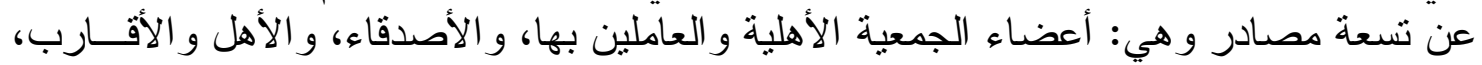

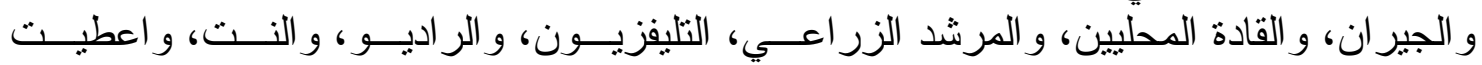

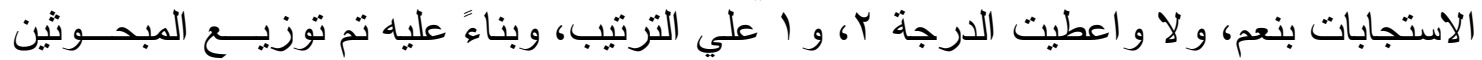

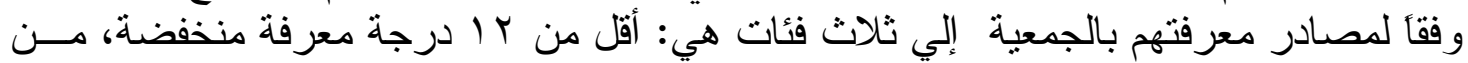

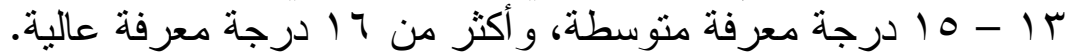

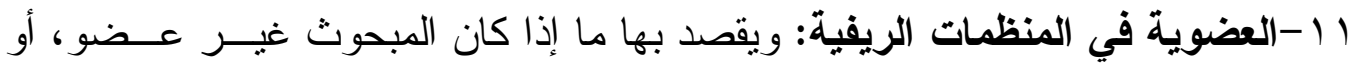

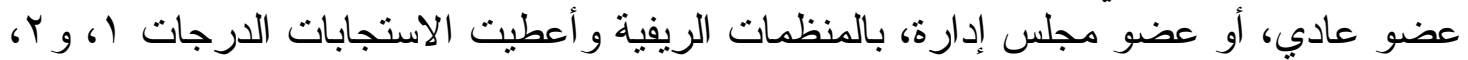

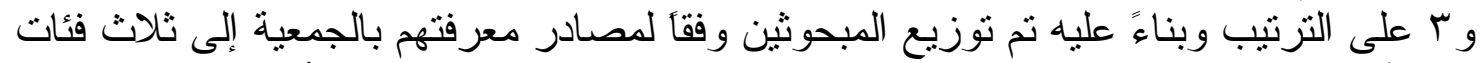

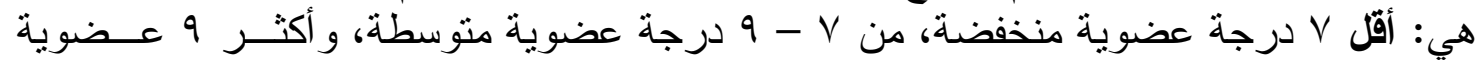

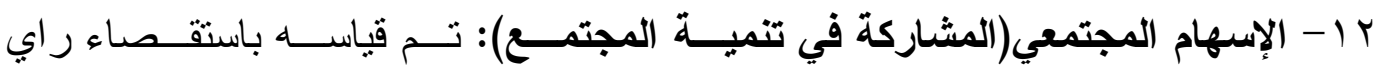

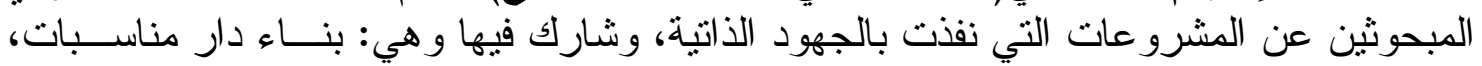

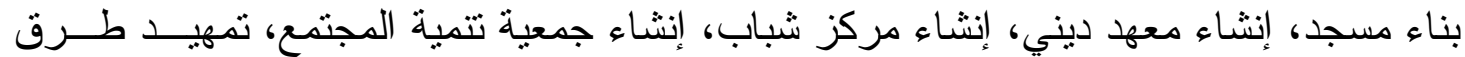

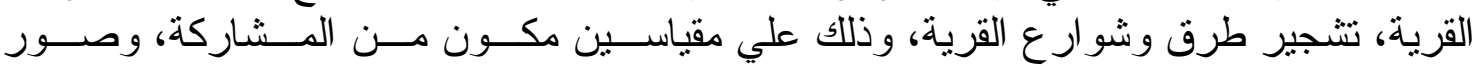

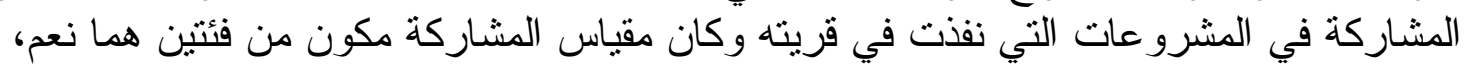

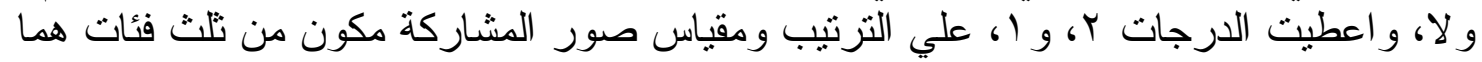

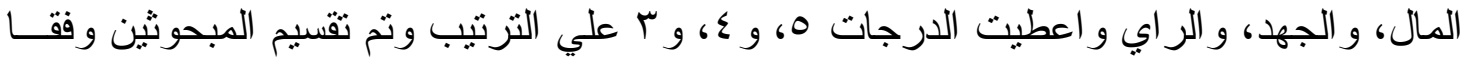

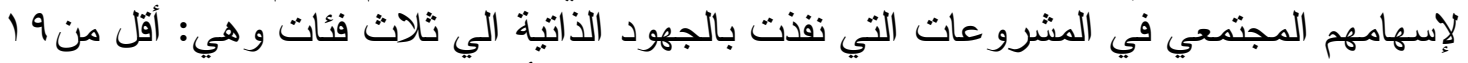

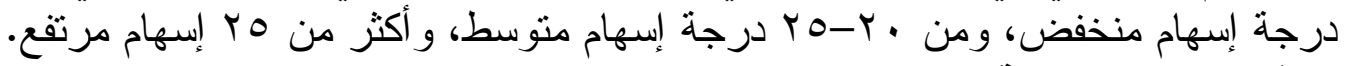

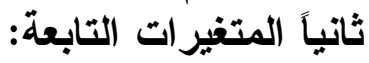

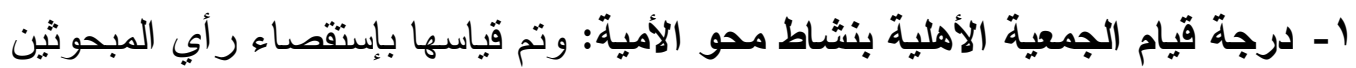

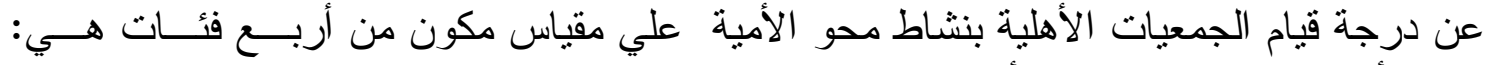

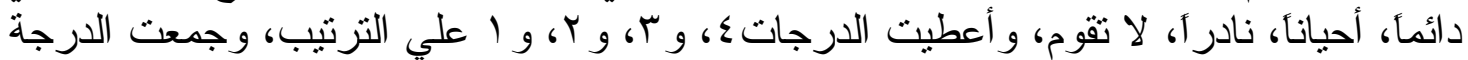

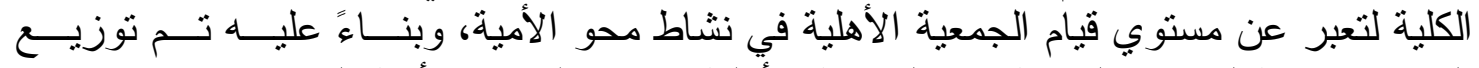

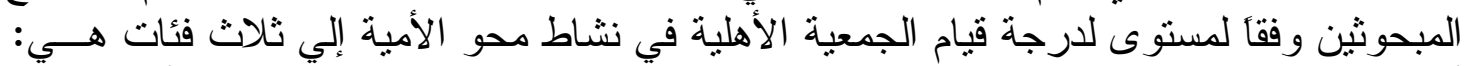

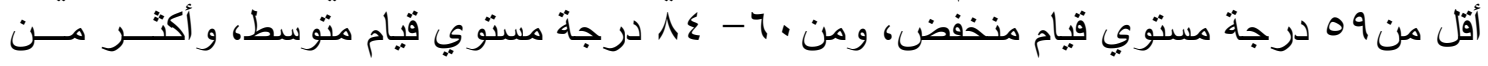

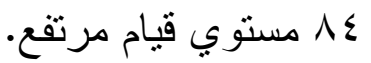

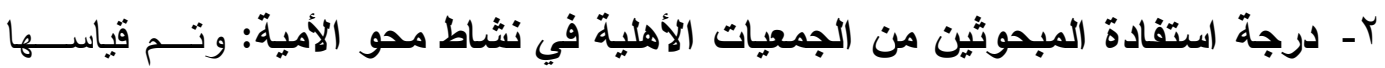

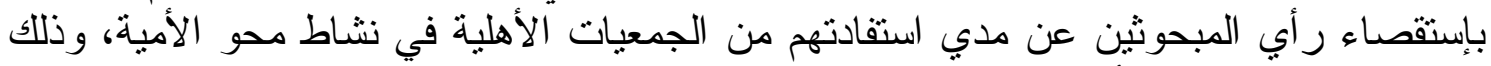

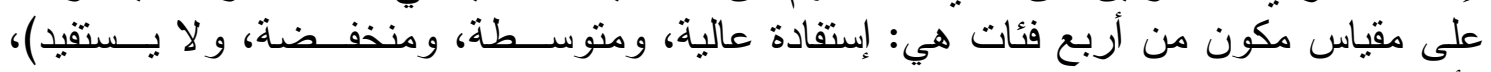

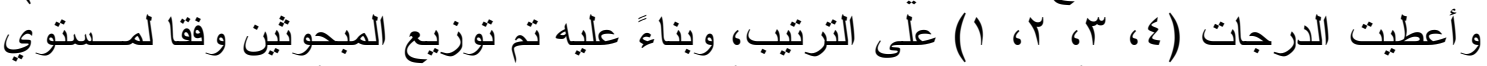

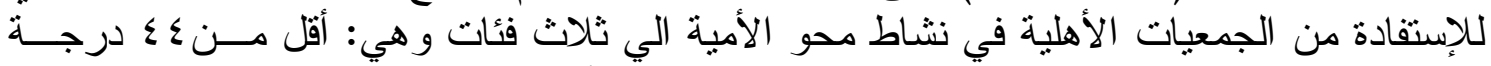

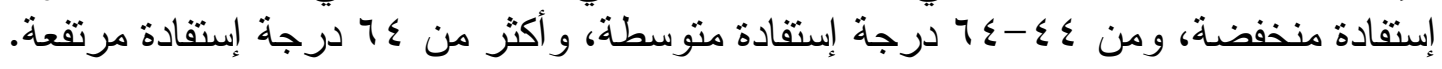
اولاً: الخصائص الثخصية و الاجتماعية والاقتصادية للمبحوثين: - 
جدول رقم (1). توزيع المبحوثين وفقا للخصائص الثخصية، والاجتماعية، والاقتصادية

\begin{tabular}{|c|c|c|c|c|}
\hline$\%$ & عدد & 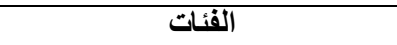 & المتفيرات البحُّيَّة & p \\
\hline$T V, \pi$ & TYE & من & \multirow{3}{*}{ 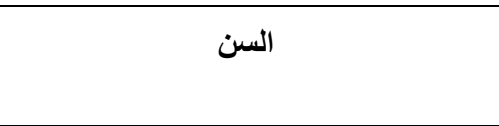 } & \multirow{3}{*}{1} \\
\hline rq, & 91 & من بr-r_لاقل من 9 ؛ & & \\
\hline$r, r$ & 11 & من 9 ؛ فاكثُ & & \\
\hline $01, \varepsilon$ & $1 \mathrm{VI}$ & ذكر & \multirow{2}{*}{ 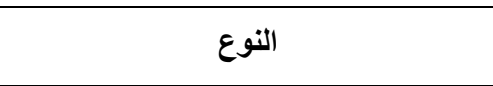 } & \multirow{2}{*}{ r } \\
\hline$\{\Lambda, \uparrow$ & 174 & أنثي & & \\
\hline$r v, v$ & 94 & أقلّ منه افراد & \multirow{3}{*}{ علد أفرد الأسرة } & \multirow{3}{*}{$r$} \\
\hline$r \mu, \tau$ & IIT & من هحتى V أفراد & & \\
\hline$r \Lambda, \nu$ & $1 \% 9$ & أكثُز من V أفراد & & \\
\hline 09,0 & 191 & نوية انوية & \multirow{3}{*}{ نوع الأسرة } & \multirow{3}{*}{$\varepsilon$} \\
\hline$r 9, r$ & $1 \pi 1$ & ممتذة & & \\
\hline$\cdot, \mathrm{Y}$ & $\varepsilon$ & 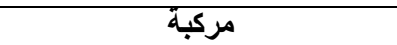 & & \\
\hline$r 0,1$ & $11 \mathrm{~V}$ & 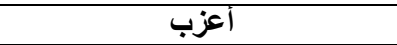 & \multirow{4}{*}{ الحالة الزواجية } & \multirow{4}{*}{ - } \\
\hline 09,1 & 199 & متزوج & & \\
\hline$r, \cdot$ & 1. & 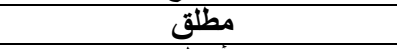 & & \\
\hline$r, 1$ & $\mathrm{~V}$ & 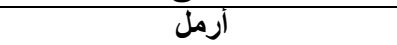 & & \\
\hline 01,1 & IV. & يعمل & \multirow{2}{*}{ الحالة العملية } & \multirow{2}{*}{9} \\
\hline$\{\Lambda, 1$ & $17 \pi$ & لا لا يعمل & & \\
\hline $\mathrm{V}, \mathrm{\Lambda}$ & $r 7$ & الزراعة فقط & \multirow{3}{*}{ المهنة } & \multirow{3}{*}{$v$} \\
\hline$r \mu, \xi$ & $V \lambda$ & الزراعة ومهنة أخري & & \\
\hline$\uparrow \Lambda, \Lambda$ & rYq & مهنة أخري فقط & & \\
\hline$\sum v, 1$ & $10 \mathrm{~V}$ & لا يحوز & \multirow{4}{*}{ سعة الحيازة الزراعية للاسرة } & \multirow{4}{*}{$\wedge$} \\
\hline$r \leqslant, 1$ & $11 \leqslant$ & أقل من r ق قيراط & & \\
\hline IY,T & $\varepsilon r$ & من Y Y حتي آ قيراط & & \\
\hline $7, \cdot$ & $r \cdot$ & من باقَير اط فاكتُ & & \\
\hline $7 \lambda, r$ & TVV & 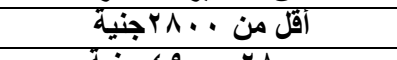 & \multirow{3}{*}{ الدخل الشهري من العمل غير زراعي } & \multirow{3}{*}{9} \\
\hline $\begin{array}{r}\mathrm{T} \cdot \mathrm{V}, \mathrm{V} \\
\end{array}$ & 79 & 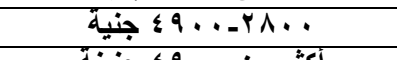 & & \\
\hline 11,1 & $r v$ & 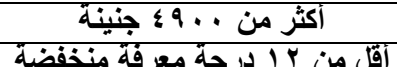 & & \\
\hline$\frac{Y, \cdot \cdot}{V Y, \Lambda}$ & $\frac{v \cdot}{r 0 q}$ & 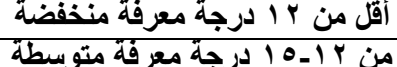 & \multirow{2}{*}{ مصادر المعرفة بالجمعية الأهلية العاملة في } & \multirow{2}{*}{1.} \\
\hline $1, Y$ & $\varepsilon$ & أكثَّ من 10 درجة معرفة عالية & & \\
\hline $9 \cdot, 1$ & $r \cdots$ & أقل من V درجة عضوية منخفضة & \multirow{3}{*}{ العضوية في المنظمات الريفية } & \multirow{3}{*}{11} \\
\hline $9, r$ & 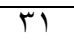 & من V-9 درجة عضوية متوسطة & & \\
\hline$\cdot, 7$ & r & أكثر من 9 درجات عضوية مرتفعة & & \\
\hline$V 7,9$ & YOY & أقل من 9 أدرجة إسهام منخفض & \multirow{3}{*}{ الإسهام المجتمعي (المشاركة في تنمية } & \multirow{3}{*}{ ir } \\
\hline 19,1 & 77 & من 9 ــ ب درجة إسهام متوسط & & \\
\hline$r, r$ & 11 & أكثُز من هY ب إسهام مرتفع & & \\
\hline
\end{tabular}

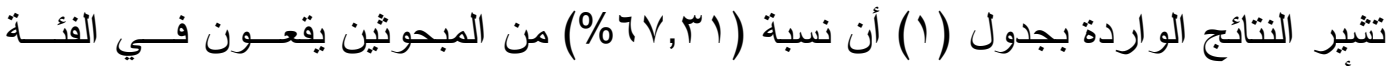

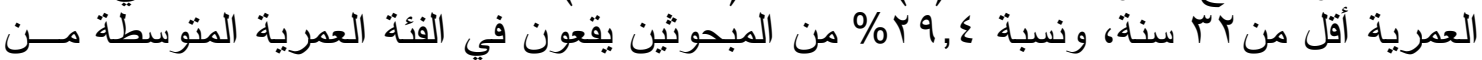

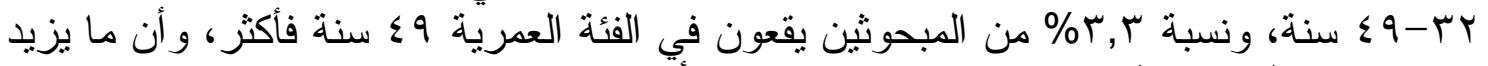

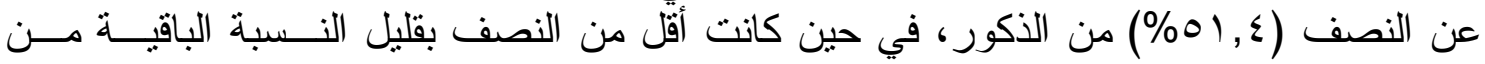

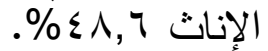

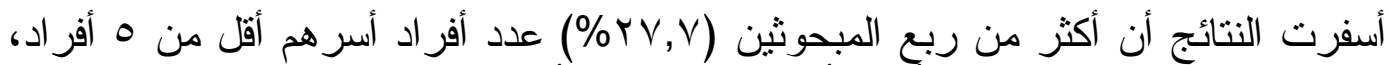

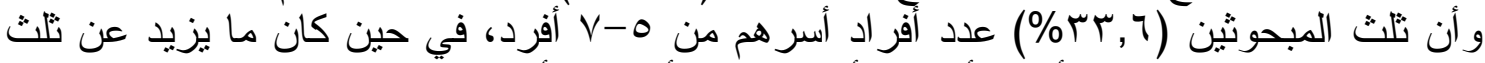

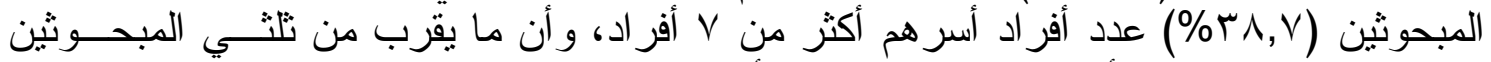

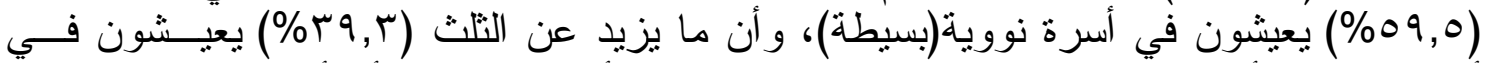

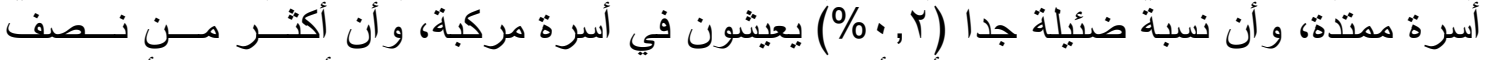

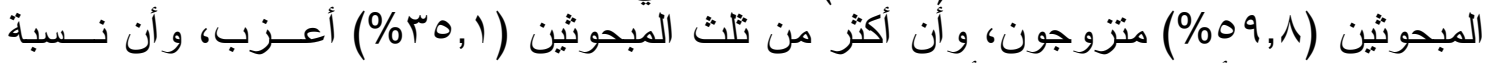

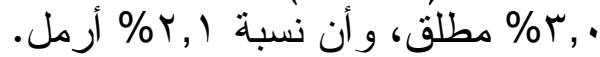




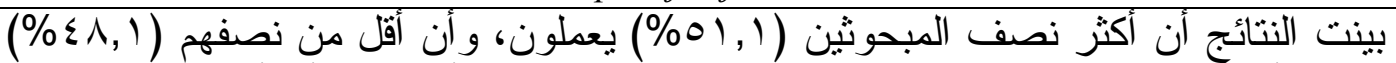

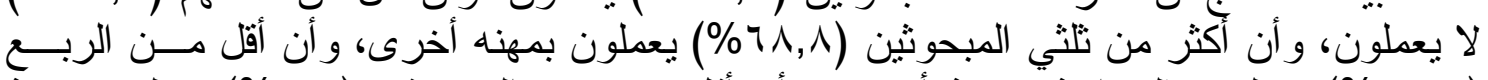

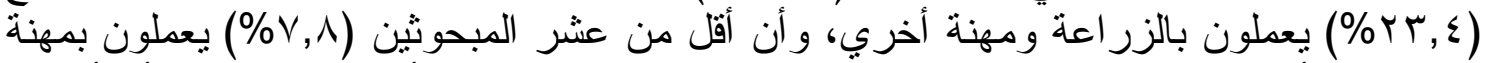

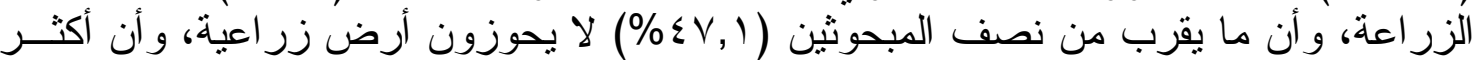

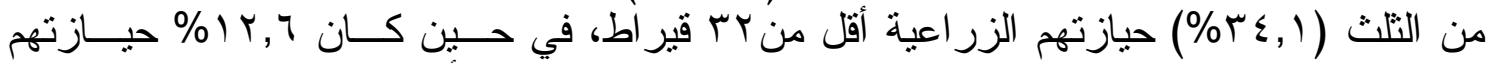

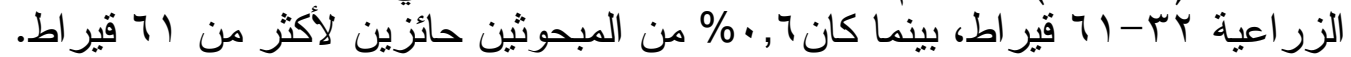

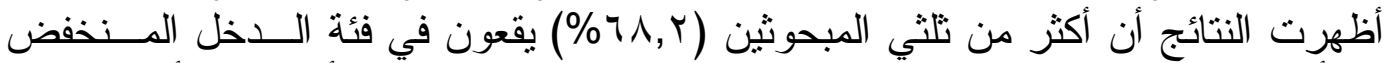

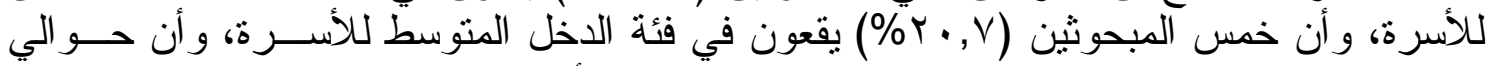

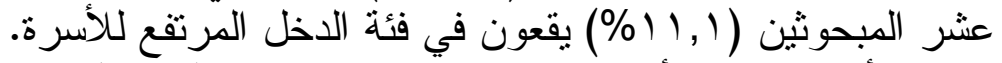

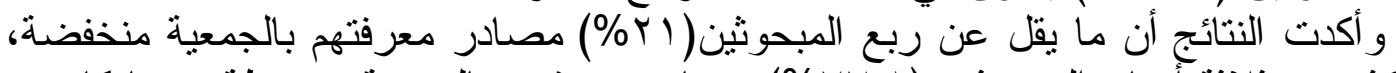

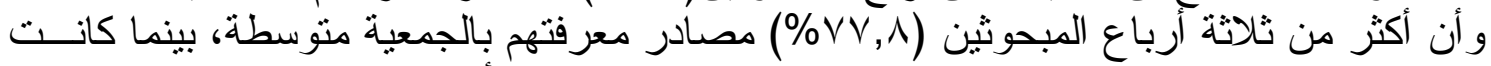

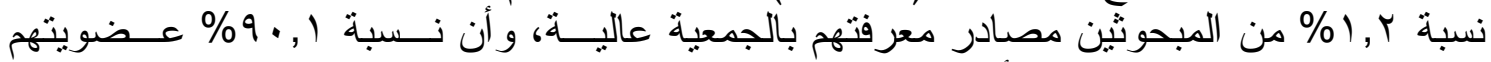

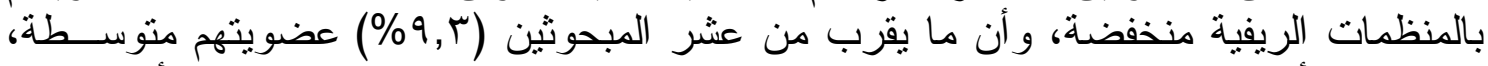

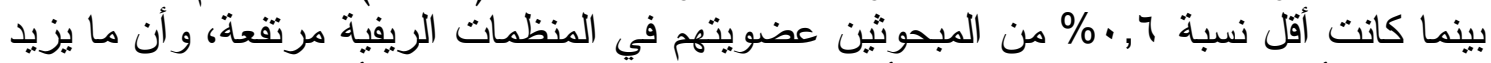

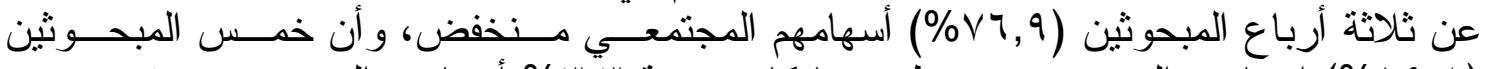

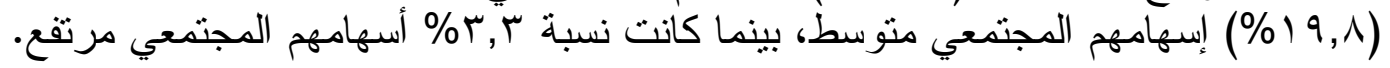

اولاً: درجة قيام الجمعيات الأهلية بنشاط محو الأمية جدول (ז). توزيع المستفيدين من الجمعيات الأهلية في نثاط محو الأمية ورايهم في درجة قيام الجمعية بنثاطها.

\begin{tabular}{|c|c|c|c|c|c|c|c|c|c|c|}
\hline \multirow{3}{*}{ | الترتيب } & \multirow{3}{*}{ المتوسطة } & \multicolumn{8}{|c|}{ درجة القيام } & \multirow{3}{*}{ قيام الجمعيات الأهلية } \\
\hline & & \multicolumn{2}{|c|}{ دائما } & \multicolumn{2}{|c|}{ أحيانا } & \multicolumn{2}{|c|}{ نادرا } & \multicolumn{2}{|c|}{ V } & \\
\hline & & $\%$ & عدد & $\%$ & عدد & $\%$ & عدد & $\%$ & عدد & \\
\hline r & $r, O r$ & 70,1 & 19 & Y r & V) & 14,9 & $r$ & - & • & تحلم فيه. \\
\hline 17 & $r, r$ & $0 r, 0$ & $\nabla \wedge$ & $1 \pi, 0$ & $\leqslant 0$ & $1 r, 9$ & $\varepsilon r$ & $r \cdot, 1$ & $7 V$ & الجمعية بتقوم بعمل ندو ات علثان تلتحق بفصول محو الأمية. \\
\hline$\varepsilon$ & $\Gamma, \xi \varepsilon$ & $09, \wedge$ & 99 & $r V, r$ & 91 & $1 \cdot, \wedge$ & rq & $r, 1$ & $\mathrm{~V}$ & الجمعية بتعرفلك مو عد بدء الدر اسة بفصل محو الأمية. \\
\hline$r$. & $r, Y)$ & $r V_{,} \cdot$ & 9. & $\varepsilon \cdot, 0$ & ro & $9, r$ & M & $r t, 1$ & $\checkmark V$ & الجمعية بتجزز الكر اسي المناسبة للجلوس عليها. \\
\hline 7 & $\Gamma, \mu \wedge$ & Or, 9 & 187 & Mo, & $11 \mathrm{~V}$ & 9,7 & Tr & $r, \xi$ & $\Lambda$ & الجمعية بتوفر الكتب و الكر اسات و الأقلام و السبورة اللازمة لعطلية تعليم \\
\hline Y) & T,YV & $19, r$ & $7 \varepsilon$ & Yo, 1 & $\wedge \uparrow$ & $1 \wedge, \cdot$ & 7. & $r 7,9$ & $r \mu$ & الجمعية بتوفر للك فديو أو تسجيل يساعدك في تعليمك. \\
\hline 11 & $r, r$. & 01,1 & $\vee \cdot$ & r., & ITY & $\varepsilon, 0$ & 10 & $\vee, \wedge$ & YY & الجمعية بنوفر مدرسين كويسين علثان يعلموك. \\
\hline 9 & $r, r$ & $0 \xi, V$ & $\overline{A T}$ & $r \cdot, T$ & $\cdot r$ & $\checkmark, 0$ & ro & $V, r$ & $r \varepsilon$ & الكتاب اللي بندهوللك الجمعية سهل وو اضح. \\
\hline 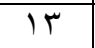 & $r, Y V$ & $1, \varepsilon$ & (1) & $\Gamma \varepsilon, 0$ & 10 & $\varepsilon, r$ & $1 \varepsilon$ & 9,9 & T & المعلم كان بيعلكك الحروف وبيجبلك أنثكال وصور للحروف. \\
\hline r. & r, זی & r, & $1 \varepsilon$ & YO, & $\Lambda \varepsilon$ & Yl, & VY & $r \cdot, 9$ & $1 \cdot r$ & المعلم اللي في الفصل كان بيستخدم الفذيو أو التسجيل لتعليمك. \\
\hline$\Lambda$ & r, ru & 09,0 & 191 & YY,1 & $\Lambda V$ & $7, \cdot$ & $r \cdot$ & $\wedge, \Sigma$ & YA & المعلم بيعلكك ازي تكتب الحرف في أول الكلمة وفي وسطها وفي آخرها \\
\hline 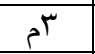 & r,OY & r, & 1. & $r \wedge, 0$ & 0 & $7, \cdot$ & $r \cdot$ & $Y, \Sigma$ & $\Lambda$ & المعلم كان بيعلمك ازي تكون من الحروف كلمات. \\
\hline مإ & $r, r \cdot$ & 9,1 & 77 & $r T, q$ & 14 & $1 T, Y$ & $\varepsilon \leqslant$ & $r$, & 1 . & المعلم اللي في الفصل كان بيخليك تطلع تكتب على السبورة. \\
\hline $1 \leqslant$ & $r, 1 r$ & $\varepsilon 9, Y$ & $7 \varepsilon$ & $10, r$ & 1 & $r \leqslant, 0$ & 10 & $\cdot, 9$ & r & الجمعية بتحدد مو عد حضورك علي حسب الوقت اللي بيكون مناسب ليك \\
\hline 1 . & $r, r$ & $T, 0$ & $\nabla \wedge$ & $r, r$ &.$\varepsilon$ & $\Lambda, \vee$ & rq & 7,7 & Yr & الجمعية بتعرفك ميعاد الامتحان قبله بفترة كافية. \\
\hline IV & $r, q \leq$ & 9,9 & r & $r \cdot, 1$ & $7 V$ & $\mu \varepsilon, 0$ & 10 & $0, \xi$ & 11 & الجمعية بتقدملك حو افز تشجعك على الاستمر ار في فصل محو الأمية. \\
\hline 10 & $r, 11$ & $r V, \Lambda$ & $r$ & $\varepsilon \Gamma, 0$ & $1 \leq 0$ & $1 \cdot, 0$ & ro & $\Lambda, 1$ & rV & الجمعية بتعلمك صانعة أو حرفة بجانب تعليمك القر اءة و الكتابة. \\
\hline IT & $r, Y q$ & Or, & $\nabla \varepsilon$ & $r \cdot, l$ & VI & $Y \varepsilon$, & $\wedge$. & $r, \tau$ & ir & الجمعية بتابع حضورك في فصل محو الأمية بصفة دورية. \\
\hline 0 & $r, r q$ & $09, \wedge$ & 99 & $r v, \cdot$ & 9. & 7,7 & Tr & 7,7 & Tr & الجمعية بتقام مو اد دينية تفيدك في معرفة أمور الدين. \\
\hline מו & $r, Y q$ & $\varepsilon \wedge$, & 17. & $\Gamma \leqslant, 0$ & 110 & 17,0 & 00 & $\cdot, 9$ & $r$ & الجمعية بتعلمك إز ابي نقدر تحل المشاكل اللي بتقابلك في حياتك \\
\hline$r$ & $r, 0 \leq$ & $\pi, \Sigma$ & YII & $r T, \Sigma$ & VA & $7, \cdot$ & $r \cdot$ & $V, Y$ & $r \varepsilon$ & الجمعية علمتلك حاجات كتير غيرت سلوك حياتلك للأحسن. \\
\hline 1 & r, & $\Lambda \cdot, 0$ & rYA & $\mathrm{V}, \wedge$ & ry & 7,9 & KT & $\varepsilon, \wedge$ & 17 & الجمعية عرفتلك ازي تقدر تر اعي ابنائك وتربيهم كويس. \\
\hline tra & r, rV & or,, 1 & $1 \vee 9$ & $r T, V$ & $\vee 9$ & $11, r$ & 71 & $\varepsilon, Y$ & $1 \leqslant$ & الجمعية علمتك ازي تقدر تحافظ على نظافة قرينك. \\
\hline 19 & $r, 77$ & $\varepsilon 1,1$ & $1 T \mathrm{~V}$ & $1 T, r$ & $\varepsilon \varepsilon$ & 17,9 & $0 \leqslant$ & $r q, \Sigma$ & 91 & الجمعية بتعملك رحلات بجانب محو أمينك. \\
\hline $\mathrm{V}$ & $r, \mu v$ & 9,0 & 191 & $r \varepsilon, r$ & $\Lambda 1$ & $1 \cdot, \Lambda$ & ri & $0, \varepsilon$ & 11 & الجمعية علمتلك خطورة الأمية في التعامل مع الآخرين. \\
\hline
\end{tabular}




\begin{tabular}{|c|c|c|c|c|c|c|c|c|c|c|}
\hline 11 & $r, \wedge \wedge$ & $\varepsilon \wedge$, & 17. & $\overline{1 \varepsilon, \varepsilon}$ & $\varepsilon \wedge$ & 10,9 & or & Y I,T & VY & الجمعية بتديلك شهادة معتمدة عند نجاحك في فصل محو الأمية. \\
\hline rt & $r, 1$. & 19,1 & $9 \vee$ & $r, r$ & 11 & 17,1 & 07 & $0 \cdot, 1$ & 179 & الجمعية بتديلك مكافأة مالية عند نجاحك في فصل محو الأمية. \\
\hline
\end{tabular}

تبين من نتائج جدول (Y) أن إجابات المستقبدين عن درجة قيام الجمعية بدور ها في نشاط

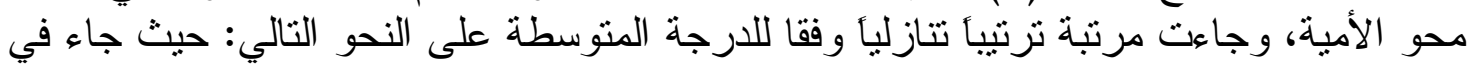

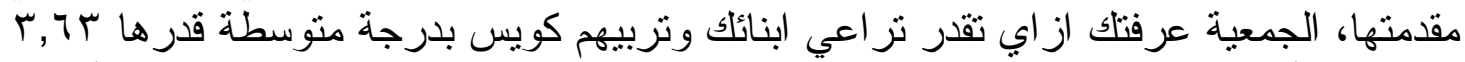

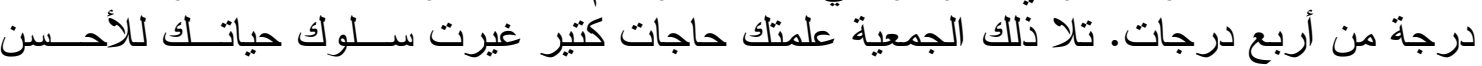

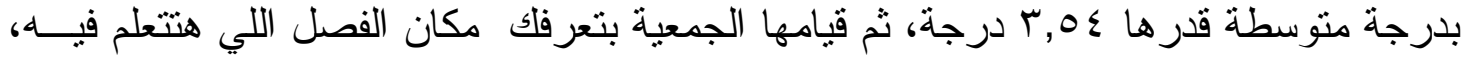

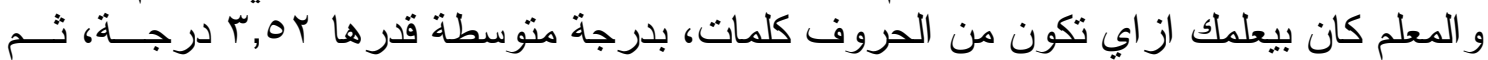

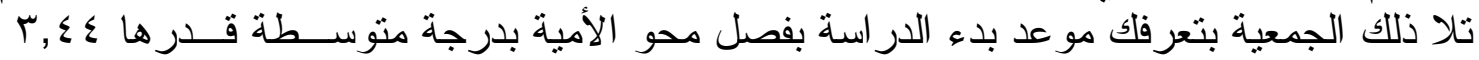

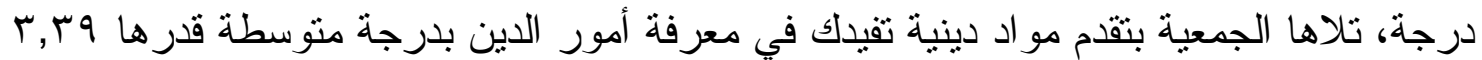

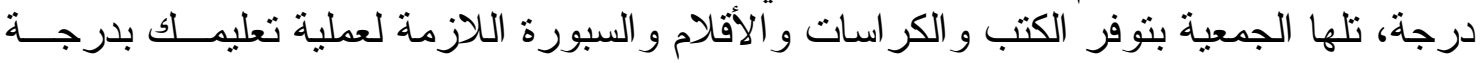

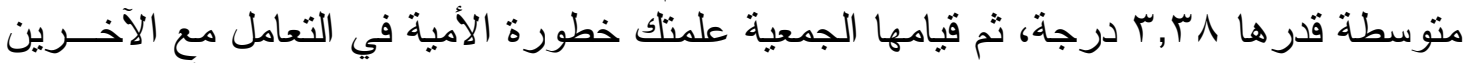

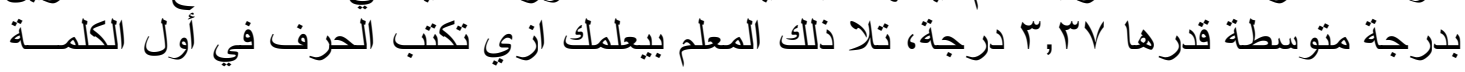

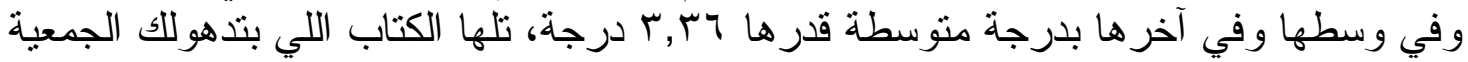

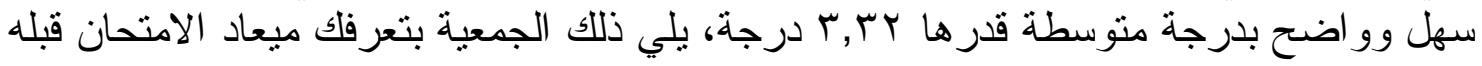

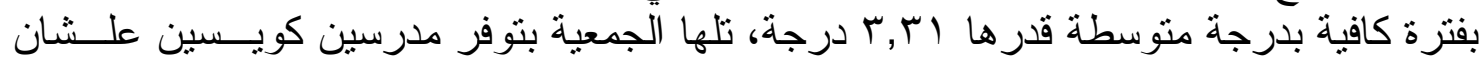

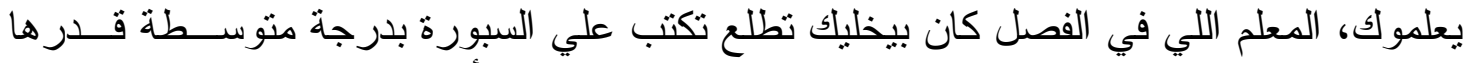

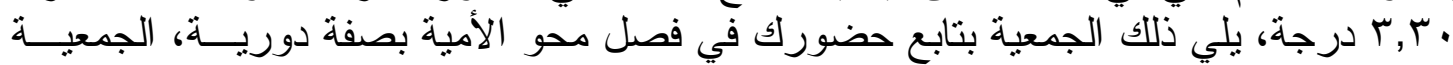

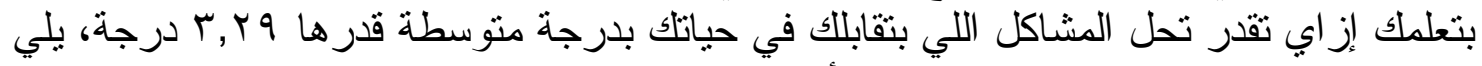

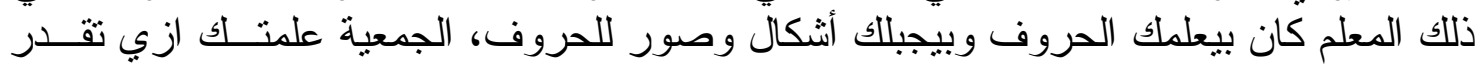

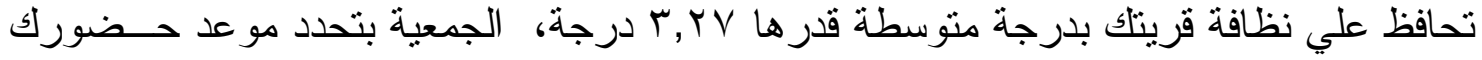

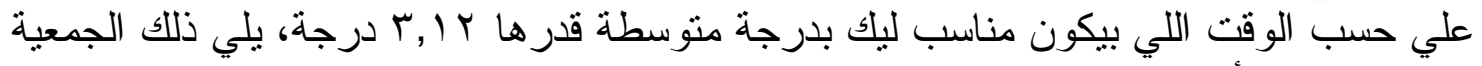

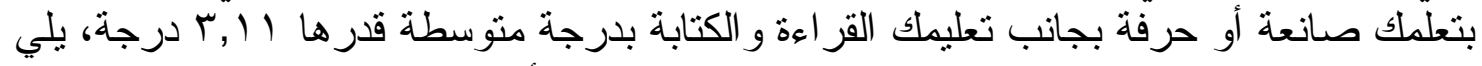

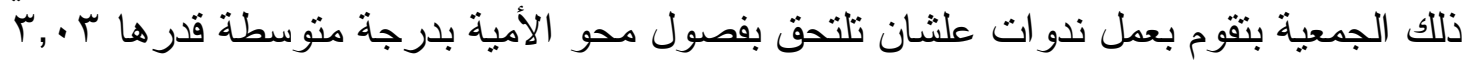

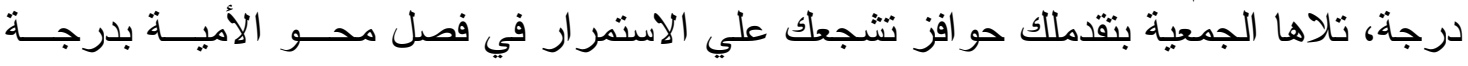

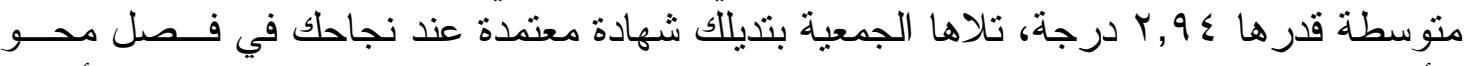

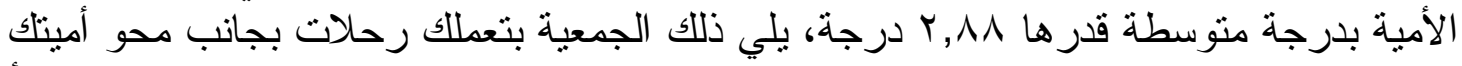

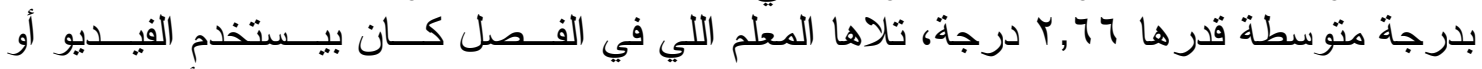

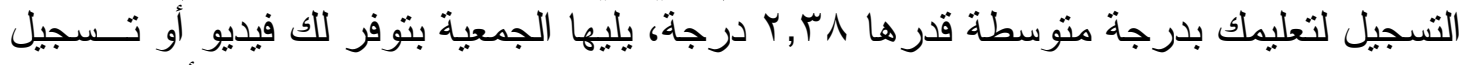

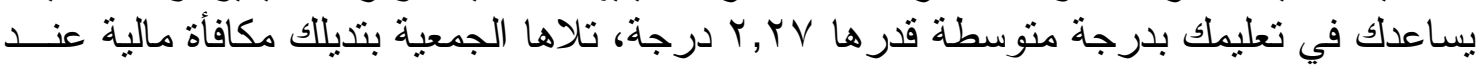

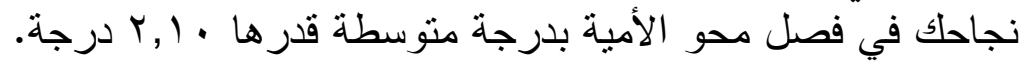

جدول رقم(ب). توزيع المبحوثين وفقاً لرأيهم في مستوي قيام الجمعيات الأهلية في نشاط محو

\begin{tabular}{|c|c|c|}
\hline$\%$ & عدد & الفئات \\
\hline 9,7 & Mr & منخفض أقل من9ه درجة \\
\hline rT, r & 111 & متوسط من 09 _ـ د درجة \\
\hline ov, 1 & 19. & مرتفع أكثر من £^ درجة \\
\hline $1 \ldots$ & אח & الإجمالي \\
\hline
\end{tabular}




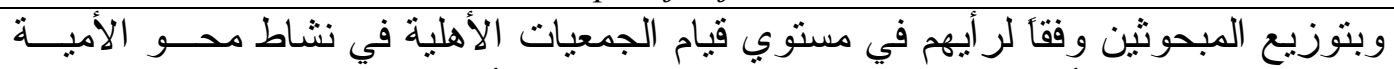

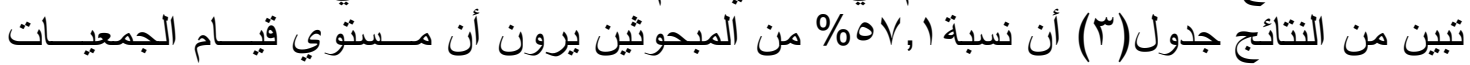

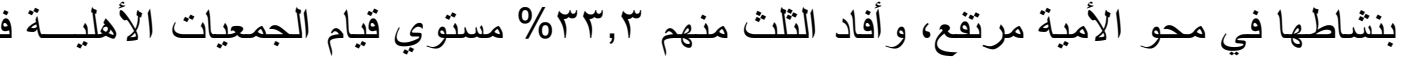

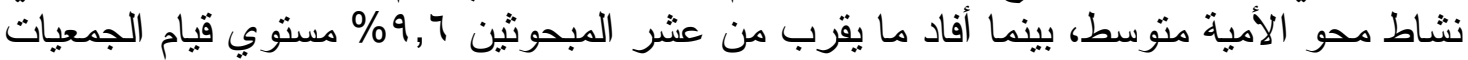

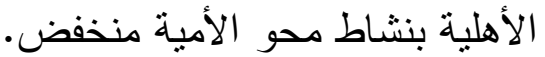

ثانياً: درجة استفادة المبحوثين من الجمعيات الأهلية بنشاط محو الأمية

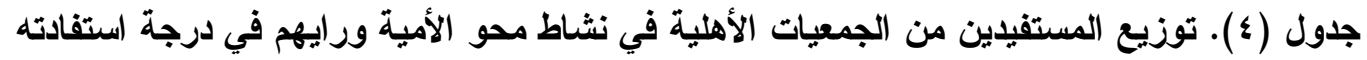

\begin{tabular}{|c|c|c|c|c|c|c|c|c|c|c|c|}
\hline \multirow{3}{*}{ الترتيب } & \multirow{3}{*}{ المتوسط } & \multicolumn{8}{|c|}{ درجة الاستفادة } & \multirow{3}{*}{ الاستفادة } & \multirow{3}{*}{ r } \\
\hline & & \multicolumn{2}{|c|}{ دائما } & \multicolumn{2}{|c|}{ أحيانًاً } & \multicolumn{2}{|c|}{ نادرا } & \multicolumn{2}{|c|}{ 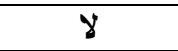 } & & \\
\hline & & $\%$ & عدد & $\%$ & عدد & $\%$ & عدد & $\%$ & عدد & & \\
\hline 9 & $\uparrow, \wedge \wedge$ & $\leqslant 0, \cdot$ & 10. & 10, & 0 . & $r r, v$ & $\vee 9$ & $17, r$ & $0 \leqslant$ & للالتحاق بفصول اللي بتعملها الجمعية الأمية & 1 \\
\hline ir & $r, 19$ & $1 r, 9$ & $\varepsilon r$ & $r \cdot, q$ & $1 \cdot r$ & $1 \wedge, 9$ & Tr & $r V, r$ & $1 Y \varepsilon$ & 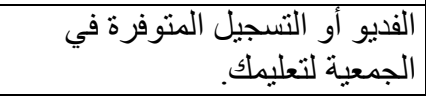 & r \\
\hline$\wedge$ & $r, r_{1}$ & $\varepsilon \varepsilon, \varepsilon$ & $1 \leq \Lambda$ & $r v, 0$ & Iro & $1 Y, 7$ & $\varepsilon r$ & $0, \varepsilon$ & 11 & في فهم من المدرس اللي بيدرسلك الأمية بالجمعية. & r \\
\hline 11 & $r, 1 \wedge$ & $\varepsilon \varepsilon, 1$ & $1 \leqslant V$ & ru, & Tr. & $1 \pi, 0$ & $\leqslant 0$ & $7, r$ & YI & الكتّاب اللي بتدرسه في فصل محو الأمية & $\varepsilon$ \\
\hline $\mathrm{V}$ & T,YY & $\varepsilon \vee, \varepsilon$ & 101 & $r \varepsilon, r$ & $11 \leq$ & $11, \mathrm{~V}$ & $r q$ & 7,7 & Tr & الأشكال والصور الحروف في تعليمك & 0 \\
\hline 7 & $r, r u$ & $01, \varepsilon$ & $|V|$ & $M, r$ & $1 \cdot \leq$ & 9,9 & r & $\vee, 0$ & ro & على السبورة. لمدا بيكتب الحروف أمامك & 7 \\
\hline $5 V$ & r r r & or, & IVT & rq, $\vee$ & 99 & $V, 0$ & ro & $1 \cdot, \wedge$ & 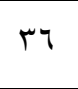 & 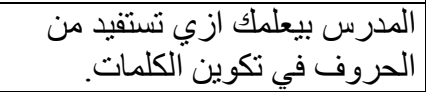 & $\checkmark$ \\
\hline ir & $r, 11$ & $\varepsilon r, r$ & $1 \leq \varepsilon$ & $r \varepsilon, \wedge$ & 117 & $11, \mathrm{~V}$ & rq & $1 \cdot, r$ & r乏 & زما بتطلك تكتب على السبورة أمام & $\Lambda$ \\
\hline $5^{\Lambda}$ & $\Gamma, Y$ & $\varepsilon 9,0$ & 170 & ( & 111 & $7, \cdot$ & $r \cdot$ & 11,1 & rV & كافية. تعرف معاد الامتحان قبله بفترة & 9 \\
\hline r & r,or & $\vee q, \cdot$ & 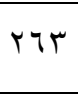 & 0,1 & iv & $0, \Sigma$ & 11 & $1 \cdot, 0$ & ro & بقيث امضية خلتتي بدل ما كنت بيصم & $1 \cdot$ \\
\hline $1 \cdot$ & $r, \Lambda$. & $r, \cdot$ & $11 \cdot$ & $r V, T$ & $9 r$ & $r 7,1$ & $\Lambda V$ & $1 r, r$ & $\varepsilon \varepsilon$ & 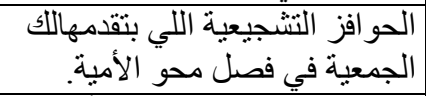 & 11 \\
\hline $1 \varepsilon$ & $r, \ldots$ & $11, \varepsilon$ & ऍ^ & $11, \mathrm{~V}$ & rq & $\varepsilon r, r$ & $1 \leq 1$ & $\Gamma \varepsilon, 0$ & 110 & تعينك في حياتكك في الجمعية صانعة أخري & 14 \\
\hline r & $r, o v$ & $\vee \wedge, I$ & r7. & $9, \cdot$ & $r$. & $0, V$ & 19 & $V, r$ & $r \varepsilon$ & الجمعية على تلكيم أنلك تكون حريص & 14 \\
\hline$\varepsilon$ & $r, \varepsilon \varepsilon$ & $7 \varepsilon$, & rIT & $r, \Lambda, \Lambda$ & $V 7$ & 7,7 & rr & 7,7 & rT & الدين. الجعية بتفيدك في معرفة أمور & $1 \varepsilon$ \\
\hline$r \wedge$ & r, & $\varepsilon \wedge, q$ & זד1 & Tr, & 114 & $V, r$ & $r \varepsilon$ & $1 \cdot, r$ & $r \varepsilon$ & أنك تقدر تحلك في الجمعية ساعدلك في اللي & 10 \\
\hline 0 & r V & 71,7 & r.o & $r T, \varepsilon$ & ২^ & $7, r$ & YI & $\wedge, \vee$ & rq & غعليمك في في الجمعية معلو مياتك للأفضل. كتير & 17 \\
\hline 1 & r,o1 & $\Lambda \cdot, r$ & YTV & $0, \Sigma$ & 11 & $V, 0$ & ro & 7,9 & r & 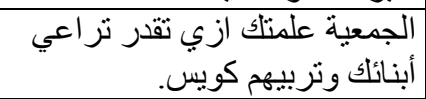 & 18 \\
\hline 11 & r.01 & rᄉ, I & ITV & $1 Y, r$ & $\varepsilon 1$ & $1 r, 9$ & $\Sigma T$ & $r 7,7$ & IYY & الرحلات اللي بتعمله الجمعية ليك. & 11 \\
\hline 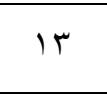 & $r, \cdot q$ & $1 \cdot, 0$ & ro & $r \varepsilon, r$ & $11 \leq$ & 9,9 & r & $\varepsilon 0, r$ & 101 & تحافظ على نظ الجمعية ازي تقافت تقر & 19 \\
\hline 10 & $1, r v$ & $r, \cdot$ & 1 . & 7,9 & rT & 10, & 0 . & Vo, & ro. & 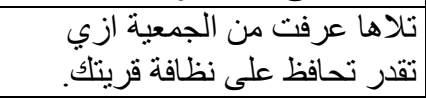 & r. \\
\hline ع & $r, \ldots$ & ro, & $\Lambda 7$ & $r, \cdot$ & $1 \cdot$ & 17,1 & 07 & $0 \leqslant, \varepsilon$ & $1 \wedge 1$ & بعد نجاحك في فصأة المي محو الأمية. المعية. & YI \\
\hline
\end{tabular}


ن

تبين من نتائج جدول (ع) أن إجابات المستقيدين من الجمعية في نشاط محو الأمية ور ايهر

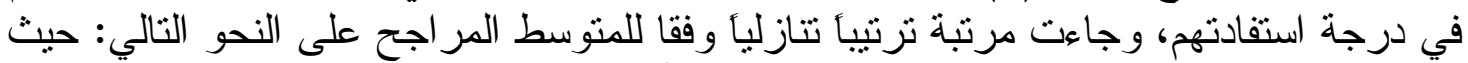

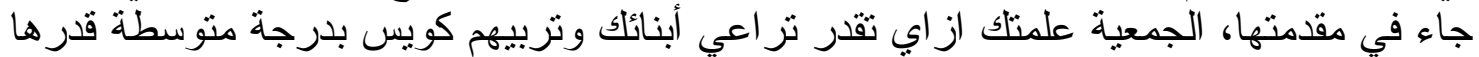

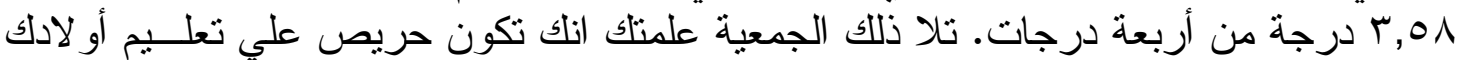

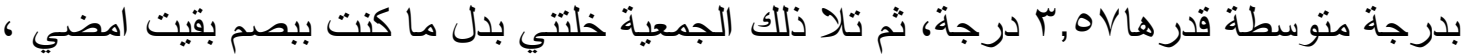

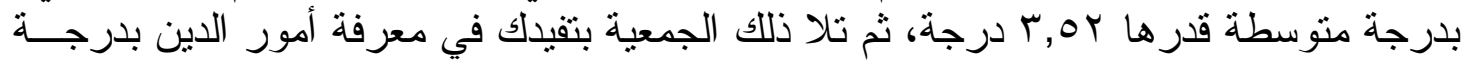

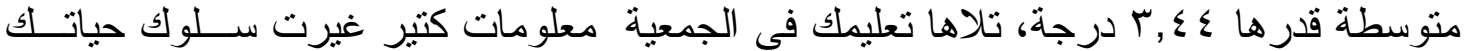

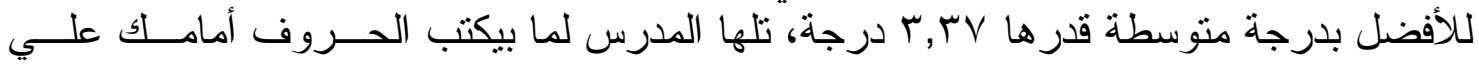

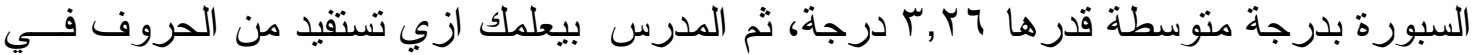

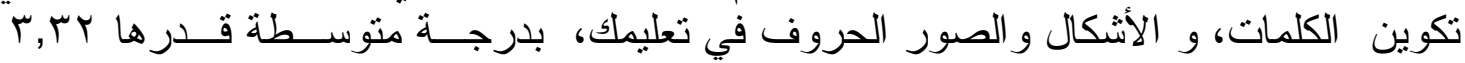

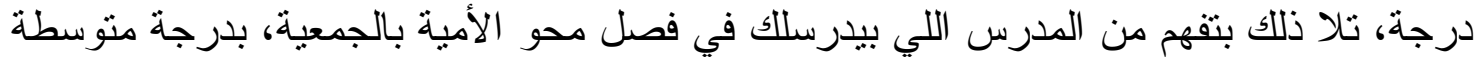

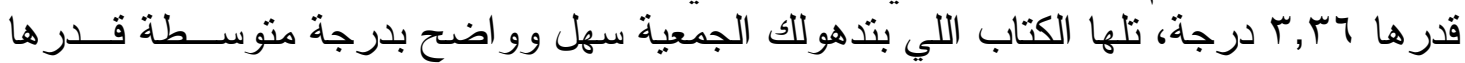
r Y, بر درجة، يلي ذلك بتفهم من المدرس اللي بيدرسلك في فصل محو الأمية، ولما تعرف معاد

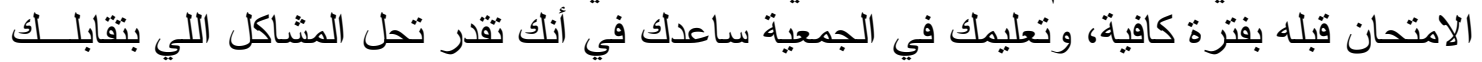

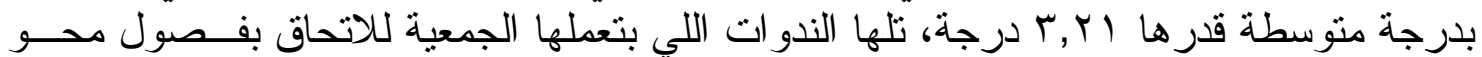

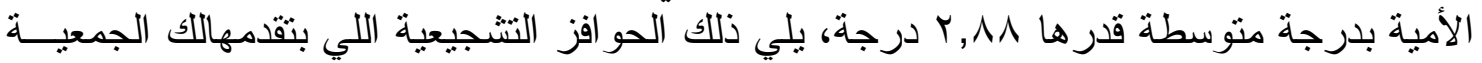

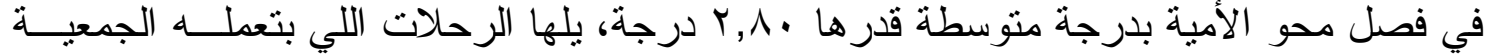

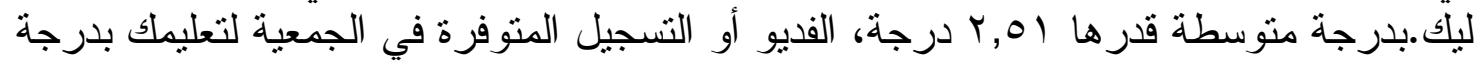

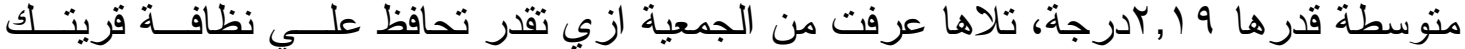

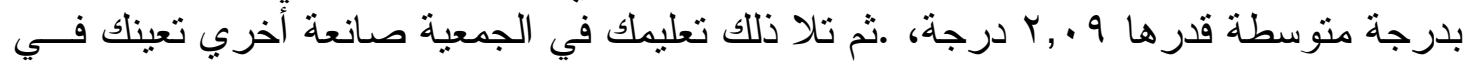
حياتلك، المكافأة المالية اللي ادتهالك الجمعية بعد نجاحك في فصل محو الأمية. بدرجة متوســـة فئة

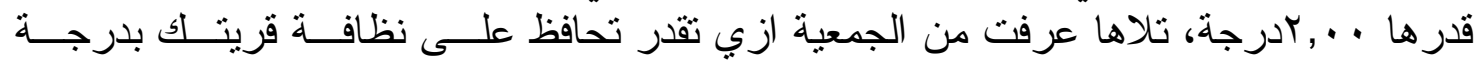

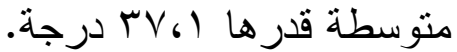
جدول رقم (0). توزيع المبحوثين وفقاً لر أيهم في مستوي استفادتهم من الجمعيات الأهلية في نـشاط

\begin{tabular}{|c|c|c|}
\hline$\%$ & عدد & الفئات \\
\hline $1 \pi, \Lambda$ & $\varepsilon 7$ & استفادة منخفضة من اقل من ؟ ـ درجة. \\
\hline$r, 1$ & $1 \cdot v$ & استفادة متوسطة من ؟ ؟-_ ؟ج درجة. \\
\hline $0 \leqslant, 1$ & 11 & استفادة مرتفعة أكثر من ع درجة. \\
\hline $1 \ldots$ & זrו & الإجمالي \\
\hline
\end{tabular}

وبتوزيع المبحوثين وفقا لر أيهم في مستوي استفادتهم من الجمعيات الأهلية في نشاط محو

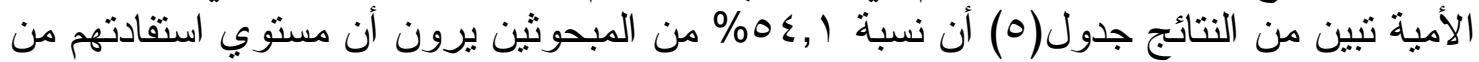

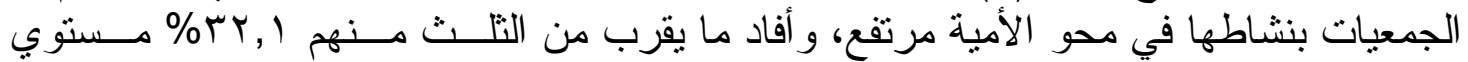

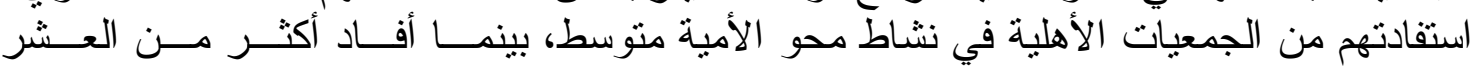

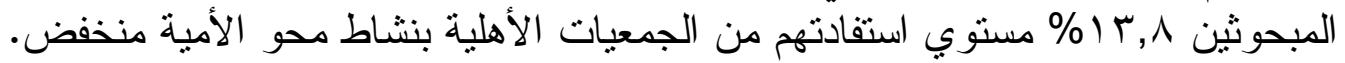
ثالثاً: العلاقة الإرتباطية بين المتغير ات البحثية وبين مستوي قيام الجمعيات الأهلية بنشاط محو الأمية. 


\begin{tabular}{|c|c|c|}
\hline \multicolumn{3}{|c|}{ 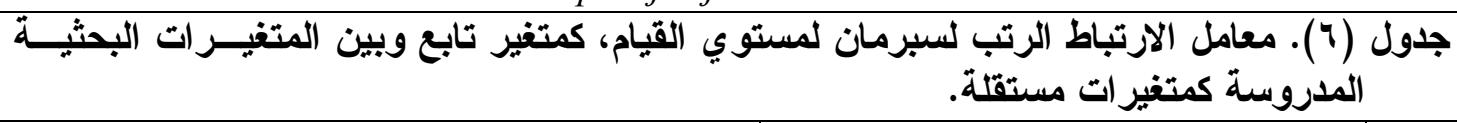 } \\
\hline معامل أرتباط الرتب لسبرىمان & المتغيرات البحثية & p \\
\hline${ }^{*} \cdot, \mid r \wedge$ & 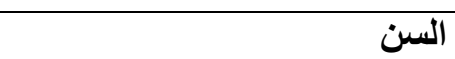 & 1 \\
\hline ** • , ז. & عدد أفراد الأسرة & $r$ \\
\hline$* * \cdot, r \cdot Y_{-}$ & إجمالي سعة الحيازة الزراعية & $r$ \\
\hline$* *, \mu, \tau$ & إجمالي الاخل للأسرة & $\varepsilon$ \\
\hline **., 104 & إجمالي مصادر المعرفة بالجمعية & 0 \\
\hline$\cdot, 77_{-}$ & إجمالي العضوية في المنظمات & 7 \\
\hline$\cdot, \mathrm{V} V_{-}$ & إجمالي الاسهام المجتمعي & $\mathrm{V}$ \\
\hline
\end{tabular}

"معنوي عند 1., *.,

"معنوي عند 0.,.

مستوي القيام: أظهرت نتاج جدول (T) وجود علاقة ارنباطية طردية عند مستوي معنوية

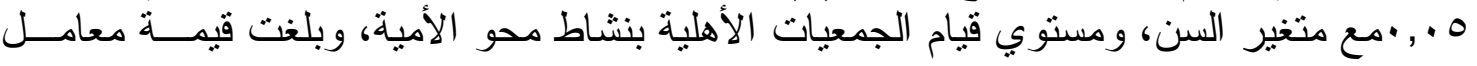

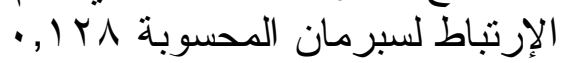

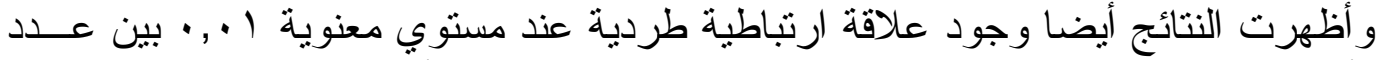

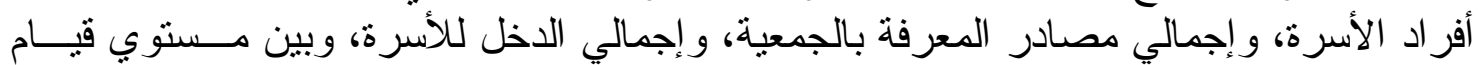

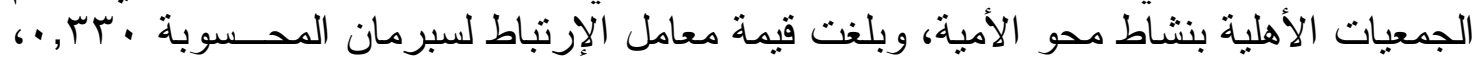

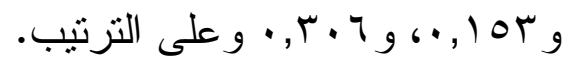

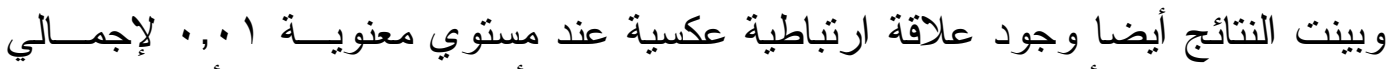

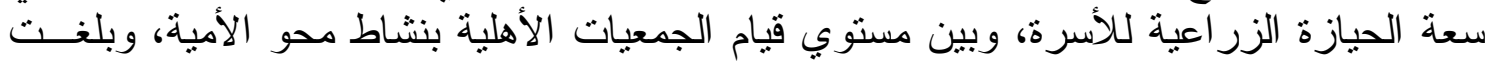

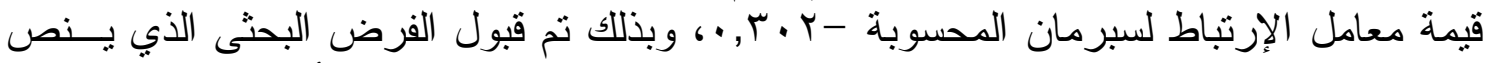

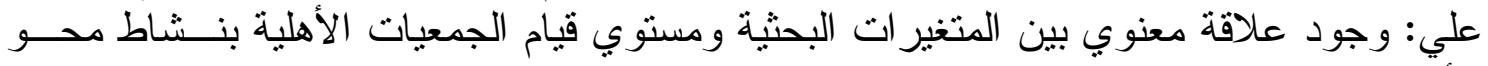

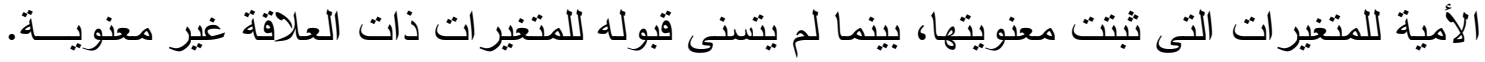
وبذلك تحقق الهدف من البحث جزئيا.

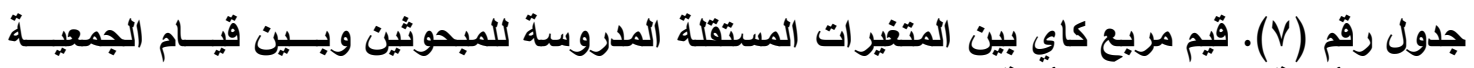
الأهلية بنشاط محو الأمية.

\begin{tabular}{|c|c|c|c|c|}
\hline درجة الحرية & كا" المعدل & كا & المتغيرات المستقلة & م \\
\hline$r$ & - & 0,001 & النوع & 1 \\
\hline$\varepsilon$ & $* * \leqslant 1, \wedge 70$ & - & نوع الأسرة & $\bar{r}$ \\
\hline 7 & $* * \leqslant 0, \mu q$ & - & الحالة الزواجية & $r$ \\
\hline$r$ & - & $* * \mid \Gamma, 7 \leqslant 0$ & الحالة العملية & $\varepsilon$ \\
\hline$\varepsilon$ & - & $* * Y 7,901$ & المهنة & 0 \\
\hline
\end{tabular}

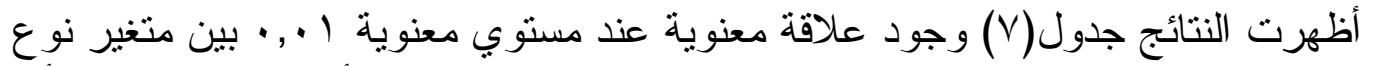

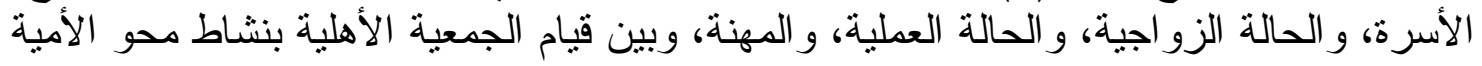

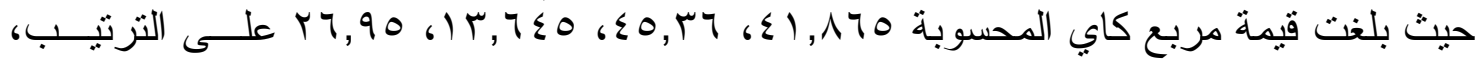
وجميعها أكبر من نظيرتهاً الجدولية.

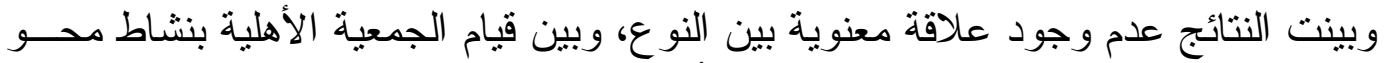

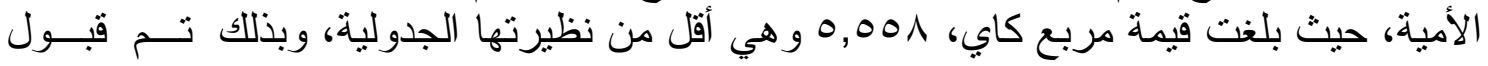

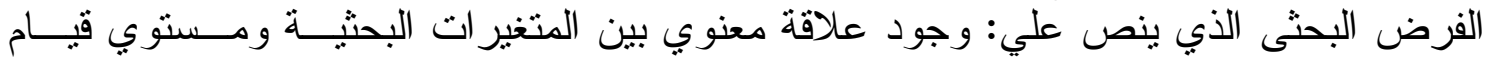




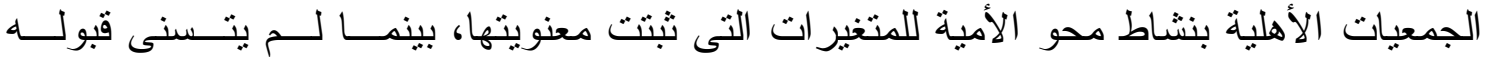

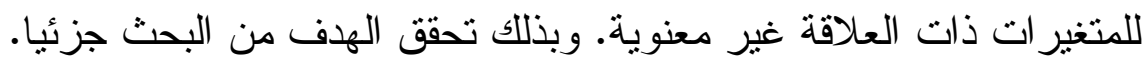
رابعاً: العلاقة الإتباطية بين المتغيرات البحثية وبين مستوى استفادة المبحوثين من الجمعيات الأهلية بنثاط

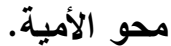
جدول (^). معامل الارتباط الرتب لسبرمان لمستوى الاستفاده كمتغير تابع وبين المتغيرات البحثية المدروسة كمتغير ات مستقلة.

\begin{tabular}{|c|c|c|}
\hline معامل ارتباط الرتب لسبرمان & المتغيرات البحثية & e \\
\hline$* ., 1<q$ & السن & 1 \\
\hline **., rr. & عدد أفراد الأسرة & $r$ \\
\hline${ }^{* *} \cdot, \Gamma \wedge r_{-}$ & إجمالي سعة الحيازة الزراعية & $r$ \\
\hline$*^{* *} .49 \varepsilon$ & إجمالي الاخل للأسرة & $\varepsilon$ \\
\hline$* *,, \backslash \wedge V$ & إجمالي مصادر المعرفة بالجمعية & 0 \\
\hline$*^{* *,, \backslash \wedge Y_{-}}$ & إجمالي العضوية في المنظمات & 7 \\
\hline$*_{.,}, K Y_{-}$ & إجمالي الاسهام المجتمعي & $\mathrm{v}$ \\
\hline
\end{tabular}

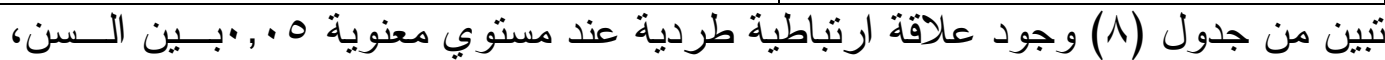

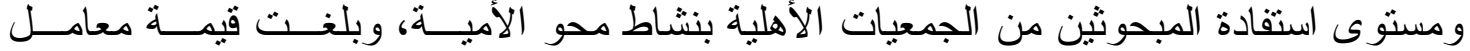

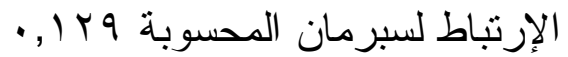

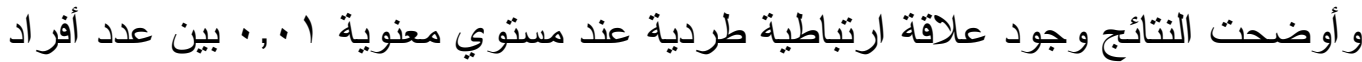

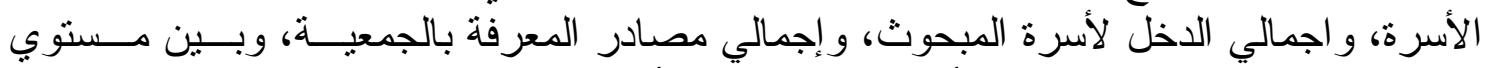

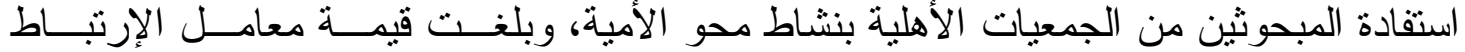

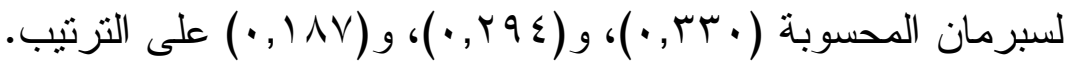

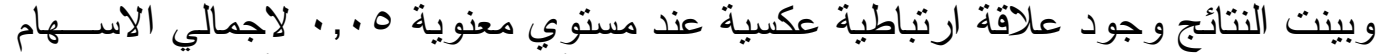

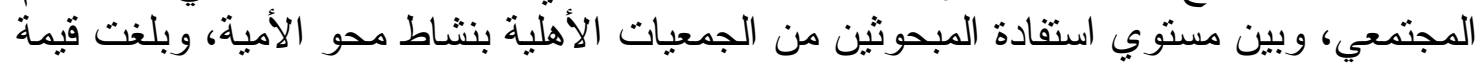

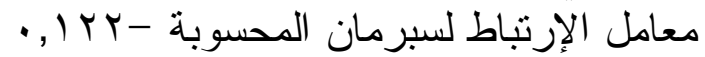

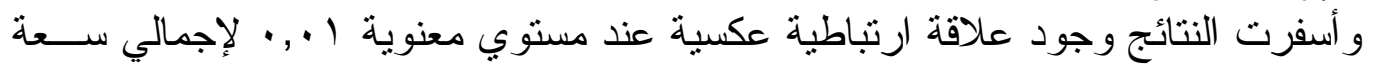

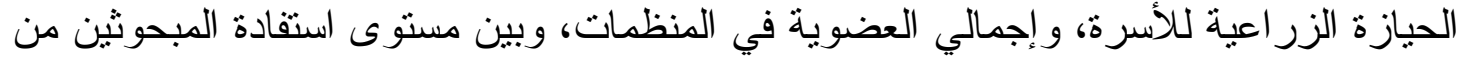

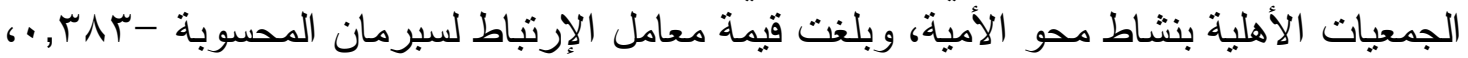

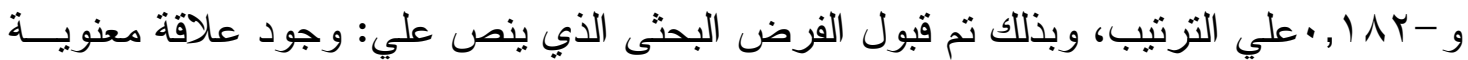

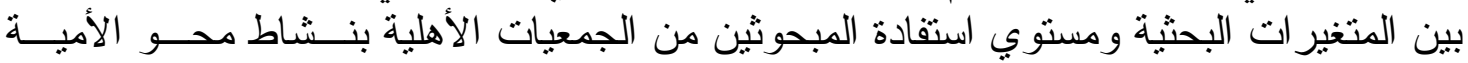
للكتغير ات التى ثنتت معنويتها.

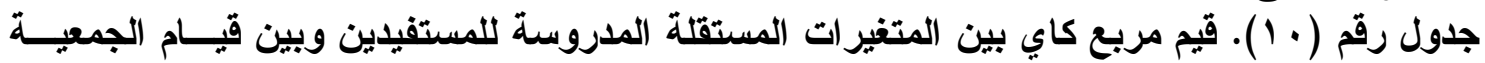
الأهلية بنشاط محو الأمية.

\begin{tabular}{|c|c|c|c|c|}
\hline درجة الحرية & كا" المعدل & كا" & المتغيرات المستقلة & 5 \\
\hline r & - & ${ }^{*} \wedge, \wedge \wedge \uparrow$ & 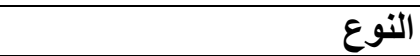 & 1 \\
\hline$\varepsilon$ & $* \star \varepsilon V, 09 V$ & - & نوع الأسرة & r \\
\hline 7 & $* * 4 r, 11 V$ & - & الحالة الزواجية & $r$ \\
\hline r & - & ${ }^{* *} \mid 7,1 Y \lambda$ & الحالة العملية & $\varepsilon$ \\
\hline$\varepsilon$ & - & **YV,QTा & المهنة & 0 \\
\hline
\end{tabular}

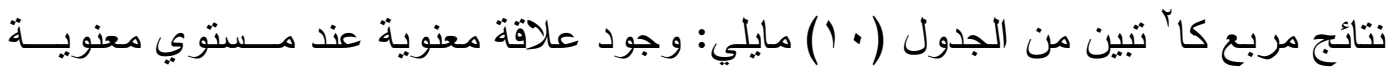

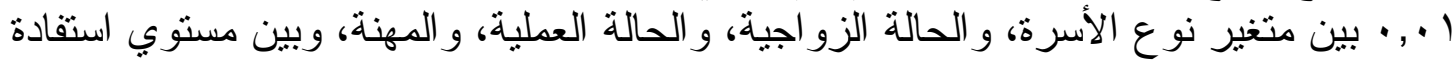

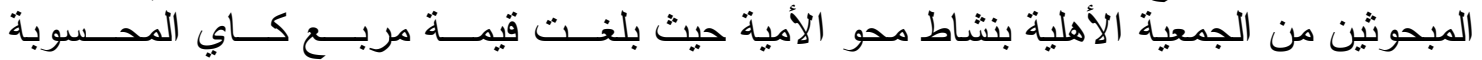




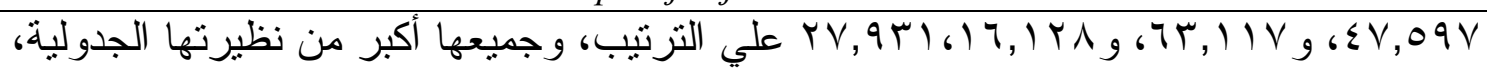

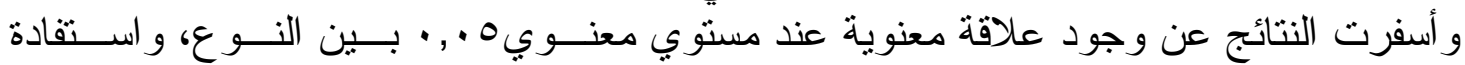

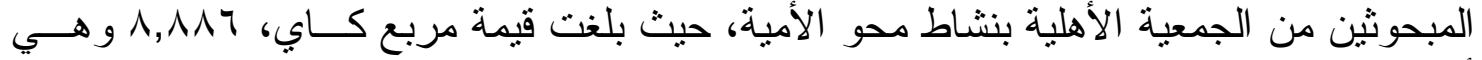

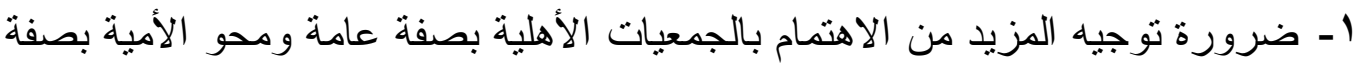

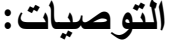

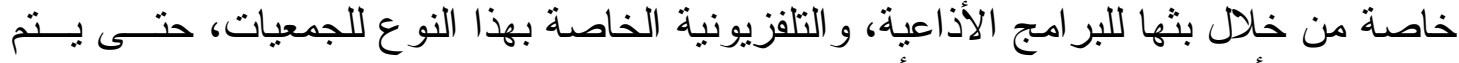
معرفتها من أكبر عدد من الافر اد الأميين.

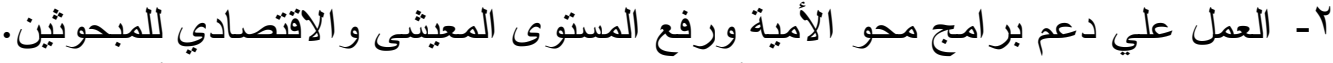

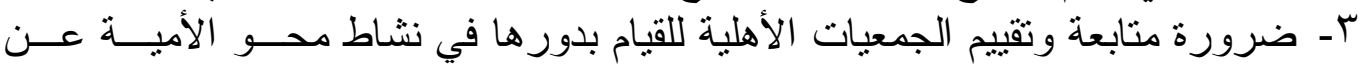

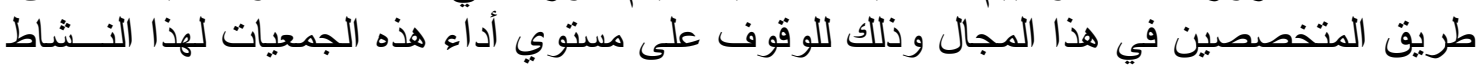

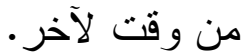

ـ - توصي الدر اسة بإجر اء دراسات مستقلية تتضمن عملية التنسيق بين الجمعيات العاملة

في نشاط محو الأمية للوقوف على أهم معوقات عملية التنسيق، ووضع آلية جيدة وفعالة لتتفيذها. المراجع

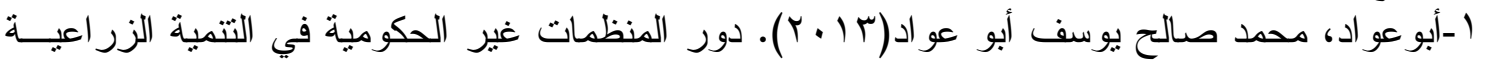

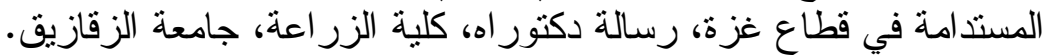

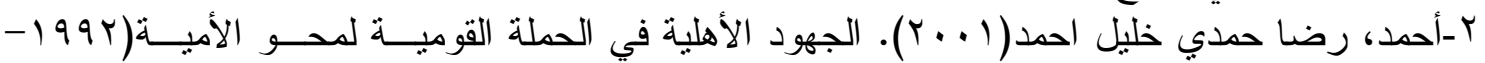

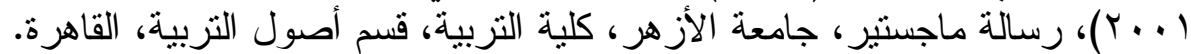

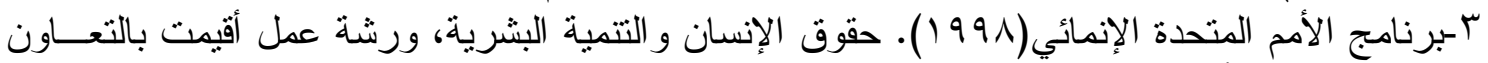

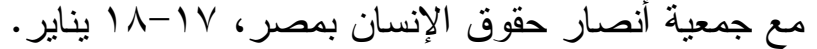

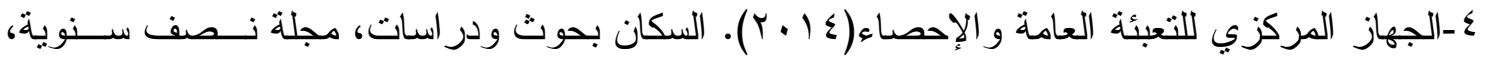

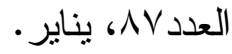

ه-حسين، أنثرف حسين (199V). الجمعيات الأهلية ودورها في التنمية في مـصـر ، مركــز البحـوث

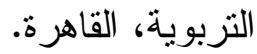
7-خاطر ، محمود رشدي خاطر، القاضي، محمود القاضي(1914). دليل العمل في محو الأمية، مركـز سرس الليان، المنوفية.

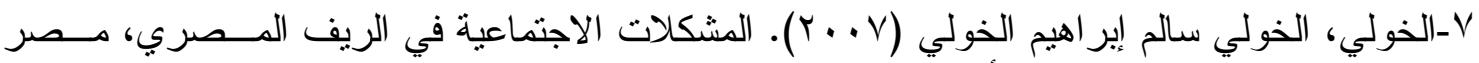
للخدمات العلمية، الطبعة الأولي. الخي.

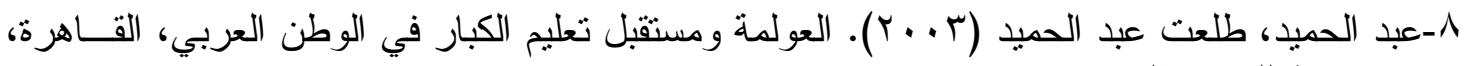
فرحة للنشر و التوزيع.

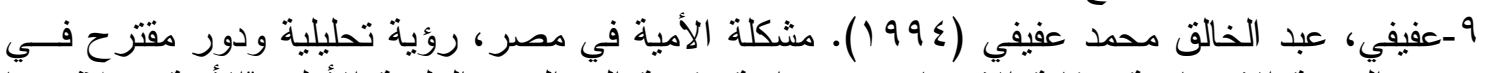

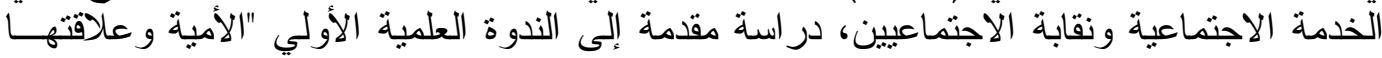

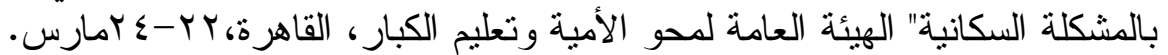

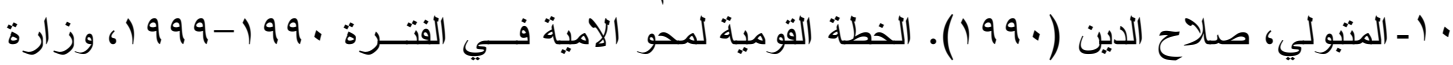

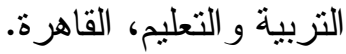

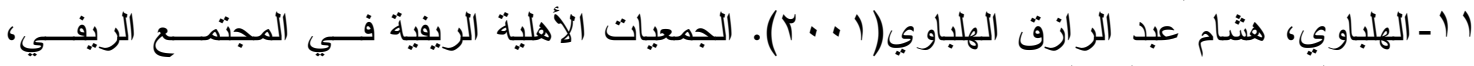
رسالة دكتور اه، كلية الزر اعة، جامعة الإسكندرية. 


\title{
Effect of some Personal Variables of the Respondents to the Degree of their Benefit from the Field of Literacy in the Achill Societies (Field Study in some Villages Assiut Governorate)
}

\section{Ebrahim Abd el Rahman A. Khalefa; Mohammed M. Ismail; Hassan Abd el Aaty Mohamed and Abdo Rmadan Abdalla}

Dept. Agric. Extension \& Rural Sociology, Fac. of Agriculture, Al-Azhar

University, Assiut Branch.

\begin{abstract}
The study aimed to determine the extent to which the NGOs in the area of literacy. From the point of view of the respondents. And to determine the degree of benefit of the respondents from the NGOs in the field of literacy. And determine the relationship between the personal and social variables of the respondents and the level of the establishment of NGOs in the field of literacy. And determine the relationship between the personal and social variables of the respondents and the level of their benefit from NGOs in the area of Mahawalip.

The total number of respondents was 2524 beneficiaries. The total number of respondents was 333 of the total number. The data were collected by means of a personal interview of the beneficiaries of the NGOs in the literacy activity by means of a questionnaire questionnaire. The correlation coefficient for Spearman for the variables of the dependent type. and the Kai box for the variables of the nominal type.
\end{abstract}

The most important results were: $67.31 \%$ were in the $16-32$ age group. Half of the respondents were 51.4 males. and more than one third (38.7\%) lived in larger families of the respondents. 59.5\% live in a simple family. half of the respondents $(51.1 \%)$ work. and nearly two thirds of the respondents $(68.8 \%)$ work in different occupations. Approximately half of the respondents (47.1\%) Do not have agricultural land. And that nearly two-thirds of the respondents 68.2 fall in the low-income category less than 2.800 pounds. And that more than three-quarters of the respondents $77.8 \%$ sources of knowledge of the Association medium. The majority of the respondents $(90.1 \%)$ are low. and more than twothirds of the respondents $(76.9 \%)$ have low social contribution.

It was also found that $57.1 \%$ of the respondents believe that the level of associations active in the eradication of illiteracy is high. And that $54.1 \%$ of the respondents believe that the level of benefit from the associations in their activity in literacy is high.

The results also showed significant correlations between the number of family members. The total income of the family of the respondent. the total number of members of the community. The total contribution of the community. The total agricultural holdings of the family. The total membership of the organizations and the level of their benefit from the literacy activities.

The results also revealed a significant relationship between the variables of family type. marital status. marita. 